This item was submitted to Loughborough's Research Repository by the author.

Items in Figshare are protected by copyright, with all rights reserved, unless otherwise indicated.

\title{
Mechanical performance of 3D printed polylactide during degradation
}

PLEASE CITE THE PUBLISHED VERSION

https://doi.org/10.1016/j.addma.2020.101764

PUBLISHER

Elsevier BV

VERSION

AM (Accepted Manuscript)

PUBLISHER STATEMENT

This paper was accepted for publication in the journal Additive Manufacturing and the definitive published version is available at https://doi.org/10.1016/j.addma.2020.101764

\section{LICENCE}

CC BY-NC-ND 4.0

\section{REPOSITORY RECORD}

Moetazedian, Amirpasha, Andy Gleadall, Xiaoxiao Han, Alper Ekinci, Elisa Mele, and Vadim Silberschmidt. 2020. "Mechanical Performance of 3D Printed Polylactide During Degradation". Loughborough University. 


\title{
Mechanical performance of 3D printed polylactide during degradation
}

Amirpasha Moetazedian ${ }^{\mathrm{a}}$, Andrew Gleadalla ${ }^{*}$, Xiaoxiao Han ${ }^{\mathrm{b}}$, Alper Ekincia, Elisa Mele $^{\mathrm{c}}$ and Vadim V Silberschmidt ${ }^{\mathrm{a}}$

a Wolfson School of Mechanical, Electrical and Manufacturing Engineering, Loughborough University, Loughborough, LE11 3TU, UK

${ }^{b}$ College of Mechanical and Vehicle Engineering, Hunan University, Changsha, 410082, China

c Department of Materials, Loughborough University, Loughborough, Leicestershire LE11 3TU, UK

*Corresponding author - Email: A.Gleadall@lboro.ac.uk

\begin{abstract}
Although widely-used biodegradable polymers have been extensively studied for conventional manufacturing processes, this is the first study considering the effect of interfacial bonds between extruded filaments - the most important aspect related to additive manufacturing on degradation at $37^{\circ} \mathrm{C}$. Its results improve the confidence in the material extrusion additive manufacturing process and negate one of the crucial unknown factors for bioresorbable products, by demonstrating that the interface degrades in a similar manner to the bulk polymer material. To do this, specially designed micro-tensile specimens were developed to analyse the degradation of $3 \mathrm{D}$-printed parts for the first time at $37^{\circ} \mathrm{C}$ and accelerated temperatures. The mechanical properties of the interface between extruded filaments ( $Z$ specimen) were compared against the control, i.e. along filaments ( $F$ specimen), under medically relevant testing conditions (submerged at $37^{\circ} \mathrm{C}$ ). Monitoring the degradation of tensile strength showed that both specimen types behaved similarly, exhibiting an initial induction period followed by a reduction in properties. Comparison of thermal and chemical properties revealed that during the early stage of degradation, crystallinity was the dominating factor, whilst at later stages, mechanical properties were mainly defined by the molecular weight and autocatalytic degradation. The findings suggest that understanding developed in the long-standing field of polymer degradation can be applied to additive-manufactured medical devices, which unavoidably contain interlayer interfaces.
\end{abstract}

Keywords: Additive manufacturing; Polylactide; Degradation; Interface; Biomedical application 


\section{Nomenclature}

AM: additive manufacturing

E: tensile modulus

$E_{0}$ : tensile modulus at day 0

$E_{A}$ : activation energy

Extruded filament: the deposited filaments from which the specimens are comprised

F: filament direction

FFF: fused filament fabrication

FDM: fused deposition modelling

G: toughness

$G_{0.5 t}$ : toughness value at normalised time 0.5

Interface: the region of joining between two extruded filaments

$M_{w}$ : weight average molecular weight

$M_{n}$ : number average molecular weight

MEAM: Material Extrusion Additive Manufacturing

PHR: peak-to-height ratio

PLA: polylactide

$T_{g}$ : glass transition temperature

$T_{m}$ : melting temperature

$T_{\text {cC: }}$ cold crystallisation temperature

$t_{0.5 \mathrm{Mw}}$ : time to halve molecular weight

$t^{*}$ : time to lose mechanical properties

Z: Z-direction (normal-to-filament direction)

$\varepsilon_{\text {break: }}$ strain at break

Ebreak 0.5t: strain at break at normalised time 0.5

$\varepsilon_{\text {max. force: strain at maximum force }}$

$\varepsilon_{\text {max. force } 0:}$ strain at maximum force at day 0

$\sigma:$ tensile strength

$\sigma_{0}:$ tensile strength at day 0

\section{Introduction}

Synthetic biodegradable polymers are widely used in numerous sectors including biomedical applications, thanks to the capability of tailoring their mechanical properties and degradation 
kinetics [1,2]. One of the most studied synthetic biodegradable polymer is polylactide (PLA), which is made of naturally-derived lactide monomers [2]. PLA possesses excellent biocompatibility and processability, with higher strength and stiffness compared to other synthetic polymers [3]. Importantly, PLA's degradation into its monomer is more environmentally-friendly, making it an attractive candidate for biomedical applications $[4,5]$. With advances in both material development and manufacturing process, the biomedical application of PLA has been expanded, ranging from orthopaedic fixation plates, screws and stents to drug-delivery devices and tissue-engineering scaffolds [2,3,6-8].

For biomedical applications of PLA, understanding its degradation kinetic and factors influencing this mechanism is vital. A PLA medical device implanted within the human body undergoes bulk hydrolytic degradation by diffusion of water molecules inside the polymer [2]. Water molecules initiate the random cleavage of ester bonds present in the polymer, and reduce its molecular weight $\left(\mathrm{M}_{\mathrm{w}}\right)$, until it no longer withstands its own weight [6]. During the early stage of degradation, the amorphous regions are preferentially hydrolysed, resulting in an increase in crystallinity of the polymer [4]. As degradation continues, the carboxylic acid end groups accumulate and act catalytically to trigger heterogeneous degradation [4]. PLA usually takes around 3-5 years to degrade fully in vivo depending on its $M_{w}$, residual monomers, crystallinity, degradation temperature and, more importantly, manufacturing process [3,9-14]. Most studies in the literature used thin films to perform degradation tests $[15,16]$. However, mechanical and thermal properties as well as degradation kinetics can substantially vary depending on the manufacturing process, especially for biodegradable polymers since they are sensitive to moisture and temperature [3].

Among the commonly used technologies, additive manufacturing (AM) has played an important role in propagating digital manufacturing in the last few years. AM gained significant attention thanks to the reduction in development cost and time by 70 and $90 \%$, respectively [17]. It allows the fabrication of intricate and customised components that are not feasible for conventional manufacturing processes such as injection moulding $[7,18]$. Material extrusion additive manufacturing (MEAM) -also referred to as fused filament fabrication (FFF) and fused deposition modelling (FDM)- is the most commonly used AM technology for thermoplastic polymers including PLA. MEAM works by deposition of a molten polymer through a heated nozzle onto the print platform to achieve a continuous extruded filament. Filaments are deposited layer by layer as the nozzle moves over the print platform (X/Y directions), which incrementally moves in $Z$ direction (normal to print platform). It is widely reported that this layer-wise printing strategy and rapid cooling of molten filament result in the major limitation of MEAM- poor bonding between extruded filament and mechanical anisotropy especially, in $Z$ direction [19]. There are numerous studies [20-25] that investigated the interface strength 
of 3D-printed parts using adapted polymer-testing standards. The results reported in the literature [20-25] are often in disagreement, likely due to a variability in test design, which makes the measurement of the real sample geometry for strength calculation difficult.

In addition to the widespread caution regarding the anisotropic properties for AM parts, continuous heating and cooling of the deposited material results in accumulation of residual stresses along with a reduction of $\mathrm{M}_{\mathrm{w}}$ and inherent viscosity of the polymer linked to thermal decomposition [26,27]. There has been limited investigation into the effects of the AM process on degradation kinetics, in particular, the degradation of interfaces between extruded filaments. On the other hand, numerous studies [13,28-30] used 3D-printed scaffolds to investigate the degradation of PLA and copolymers; however, none of these studies considered the degradation of mechanical properties of scaffolds in $Z$ direction by measuring the interface strength.

Only recently, two related studies [26,31] considered the effect of testing direction and shrinkage on degradation of PLA-based polymer. Still, only degradation at elevated temperatures was considered, without prediction of properties at physiological temperature. In these studies, tensile-testing specimens were printed according to ISO 527 standard at two directions: (i) horizontal direction (i.e. printed flat on the print platform) and (ii) vertical direction (normal to the print platform to assess interfacial bonding). The authors found that vertical specimens lost their mechanical properties and mass much faster than horizontal ones, potentially due to the weak cohesion between extruded filaments. Both studies [26,31] concluded that the weak interface was the predominant factor for faster degradation, yet the extrusion temperature and printing speed, which affect interlayer cohesion, were $3 \%$ lower and $40 \%$ higher, respectively, for vertical specimens compared to horizontal ones. Additionally, these studies only considered degradation at 50 and $70^{\circ} \mathrm{C}$ without extrapolating data back to body temperature to predict polymer lifetime. It is difficult to draw firm conclusions about the degradation of interface strength due to the complexity of current ASTM/ISO standards [32], hence, this study uses a specially designed and previously validated [19,33,34] tensile-testing specimen. Other than hydrolytic degradation, storage of PLA in an uncontrolled environment can also trigger its decomposition through physical ageing due to its low glass transition temperature $\left(T_{g}\right)$. This could result in a change in properties over time and thus, affect the shelf life of polymers [35-37]. Yet few studies [35-37] considered the ageing of PLA in the absence of water, and they all considered specimens manufactured by other processes than AM. Thus, characterising separately both physical ageing and hydrolytic degradation for 3D-printed PLA is necessary to understand both mechanisms and their influence on the material's properties and performance. 
To the best of the authors' knowledge, no study considered the degradation of interface for AM specimens at physiological temperature. Herein, specially designed micro-tensile specimens were developed to assess mechanical properties of the interface between extruded filaments to understand how the interface degrades by comparison to the bulk material. To improve the confidence in this study from a medical perspective, specimens were mechanically tested submerged at $37^{\circ} \mathrm{C}$ to replicate human-body conditions. Furthermore, the degradation was also studied at 50 and $65^{\circ} \mathrm{C}$ to understand the suitability of accelerated degradation.

\section{Materials and methods}

This section defines the materials and manufacturing process of the specimens followed by the characterisation methods.

\subsection{Materials}

Natural PLA filament (3DXTECH ${ }^{\circledR}$ branded NatureWorks ${ }^{\circledR}$ polylactide 4043D, Sigma Aldrich) with a density of $1.25 \mathrm{~g} \cdot \mathrm{cm}^{-3}$, weight average molecular weight $\left(\mathrm{M}_{\mathrm{w}}\right)$ of $240 \mathrm{kDa}$, number average molecular weight $\left(M_{n}\right)$ of $120 \mathrm{kDa}$ and melting temperature $\left(T_{m}\right)$ of $151.3^{\circ} \mathrm{C}$ was used to manufacture specimens. Mechanical properties of the material were $62.8 \mathrm{MPa}, 2.65 \mathrm{GPa}$ and 0.0507 for its ultimate tensile strength, tensile modulus and strain at break, respectively [19].

\subsection{Specimen design and additive manufacturing}

A RepRap x400 MEAM system was used to produce single-filament specimens in the form of a square box with dimensions of $45 \mathrm{~mm} \times 45 \mathrm{~mm}$ (Figure 1a) using custom GCode (a series of commands to control the printing process), for which the benefits of constant printing conditions are described in $[33,38]$. Custom GCode allows full control of nozzle movements (position, feed rate and temperature) and extrusion volume compared to traditional slicer software and is necessary to manufacture the specimens in this study. This GCode was generated with in-house software using the printing parameters shown in Table 1. Tensile testing specimens were designed at the smallest possible scale (i.e. individual extruded filaments) to allow precise characterisation of the interfacial bond by measuring the crosssectional area directly normal to the orientation of extruded filaments, which is not possible for current ASTM standard tensile-testing specimens with complex non-standardised print paths. This design also eliminated the effect of other structural factors related to the manufacturing process (infill pattern and volume; porosity; etc.). Designed specimens successfully fractured within the gauge region simply by modifying the extrusion volume along the toolpath [19]. The current design and overall dimensions were adapted from ASTM D1708 [32]. 
Table 1 Printing parameters used to produce specimens with RepRap x400 system.

\begin{tabular}{ll}
\hline Printing parameters & Value \\
\hline Nozzle diameter & $0.4 \mathrm{~mm}$ \\
Nozzle temperature & $210^{\circ} \mathrm{C}$ \\
Print platform temperature & $60^{\circ} \mathrm{C}$ \\
Printing speed & $1000 \mathrm{~mm} \cdot \mathrm{min}^{-1}$ \\
Extruded-layer height & $0.2 \mathrm{~mm}$ \\
Extruded-filament width in gauge region & $0.5 \mathrm{~mm}$ \\
\hline
\end{tabular}

In this study the effect of testing direction on the residual mechanical properties of 3D-printed PLA during degradation was considered. Thereby, two testing directions were chosen: (i) along the direction of extruded filament (denoted as F) to assess bulk properties; (ii) normal to the interface between extruded filaments (denoted as $Z$ ) to analyse manufacturing-induced anisotropy as shown schematically in Figures $1 \mathrm{~b}$ and $\mathrm{c}$, respectively.

For characterisation of the specimens, each printed box was cut into $5 \mathrm{~mm}$ wide and $45 \mathrm{~mm}$ tall specimens according to the following steps [19]:

1. The corners were cut using a specially designed tool with a razor blade to yield four walls.

2. Each wall was then cut using another specially designed tool comprising an array of seven razor blades.

3. A 12-tonne hydraulic press was used for a controlled and even cutting process by compressing the blades into walls to provide twenty-four specimens per box.

There was no edge effect due to cutting process, since the mechanical properties of different width specimens (5 and $15 \mathrm{~mm}$ ) were compared against those of injection moulded polymer and found no significant difference, as shown by authors in another study [33]. 


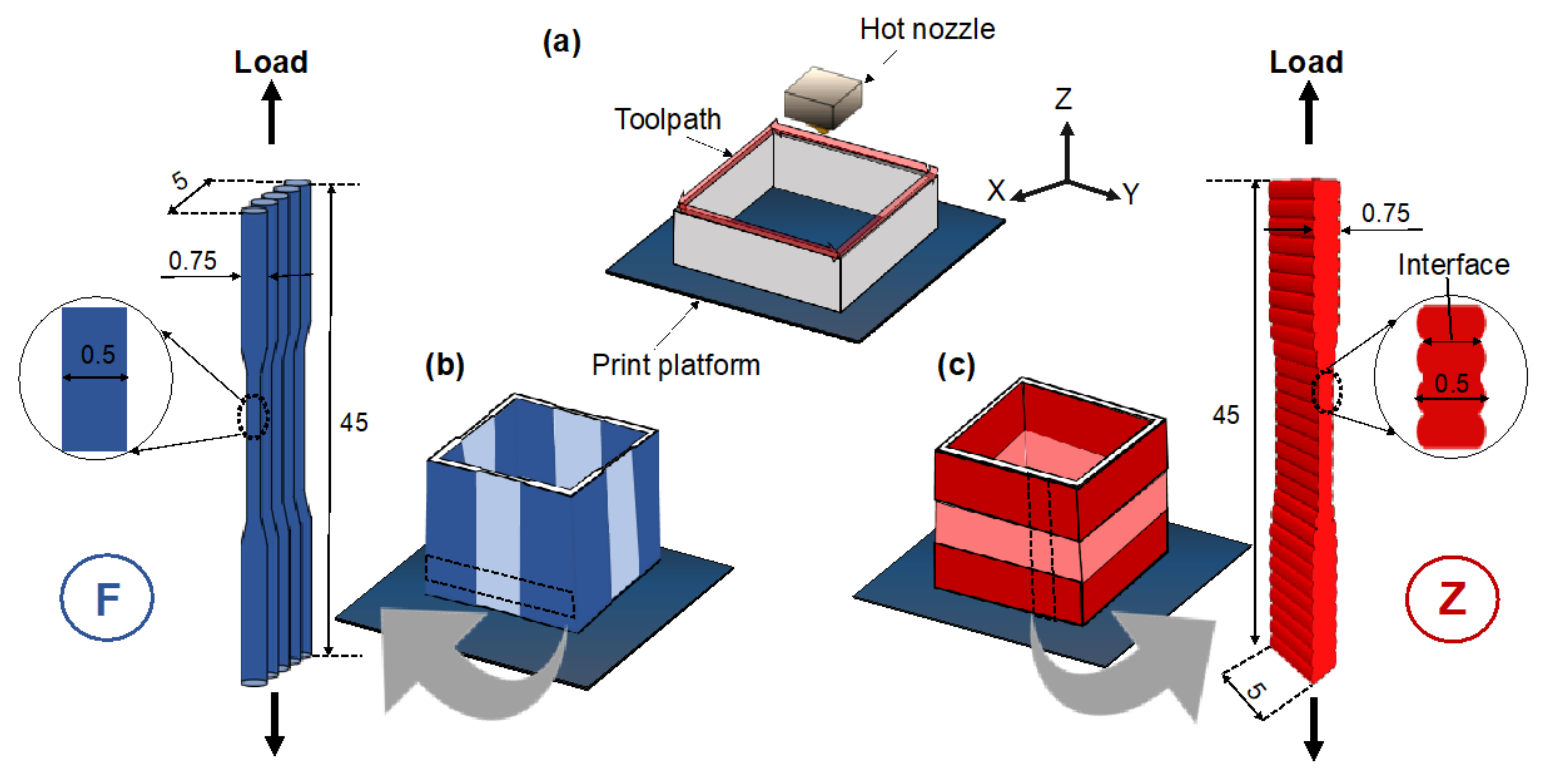

Figure 1 (a) Toolpath used for generation of single-filament walls at two testing directions: along the filament direction and parallel to the print platform (b) (denoted as F) and normal to the print platform (c) (denoted as Z). Testing direction is indicated by arrows. Dashed rectangles on the boxes represent the outline of cut specimens (all dimensions are in $\mathrm{mm}$ ).

\subsection{Physical ageing and hydrolytic degradation}

The degradation study of both $Z$ and $F$ specimens was carried out under two environmental conditions: (i) ambient laboratory conditions (room temperature, RT, and humidity) to represent physical ageing of the polymer during storage; (ii) aqueous environment, e.g. phosphate buffer saline (PBS) of pH $7.4 \pm 0.2$ at three temperatures: $65^{\circ} \mathrm{C}, 50^{\circ} \mathrm{C}$ and $37^{\circ} \mathrm{C}$ to represent hydrolytic degradation according to ISO13781:2017 [39]. The specimens were stored in $30 \mathrm{ml}$ of PBS in separate air-circulating ovens for each degradation temperature. Accelerated degradation was carried out as a screening test and compared with those degraded real-time at body temperature to assess the suitability of this method to predict the lifetime of the polymer. The PBS solution was changed regularly (e.g. every 2 days for $65^{\circ} \mathrm{C}$, every 10 days for $50^{\circ} \mathrm{C}$ and every 30 days for $37^{\circ} \mathrm{C}$ ) to maintain $\mathrm{pH}$ level within $7.4 \pm 0.2$ throughout the experiment.

\subsection{Characterisation}

\subsubsection{Water absorption analysis}

The amount of water absorption (mass increase before drying) and mass change (after drying) were assessed for hydrolytic degradation. Before degradation, the initial weight $\left(\mathrm{W}_{\mathrm{I}}\right)$ of $3 \mathrm{D}$ printed PLA specimens was measured using an analytical balance (Ohaus Adventurer, Switzerland) with precision of $\pm 0.0001 \mathrm{~g}$. Specimens were then stored in $30 \mathrm{ml}$ of PBS and, 
at each time interval, extracted from the oven and excess water was gently removed using a paper towel. Next, the wet weight $\left(\mathrm{W}_{\mathrm{W}}\right)$ of specimens was measured to calculate the mean water absorption from three measurements using the following equation [40,41]:

$$
\text { Water absorption }=\frac{W_{W}-W_{I}}{W_{I}} \times 100 \%
$$

Wet specimens were dried in a vacuum oven (OV-11 Lab Companion, Jeiotech. South Korea) at $30^{\circ} \mathrm{C}$ for $48 \mathrm{~h}$ at a set vacuum of 0.60 bar. The dry mass $\left(\mathrm{M}_{\mathrm{D}}\right)$ of specimens was measured after drying to calculate the mean mass change from the initial mass $\left(\mathrm{M}_{\mathrm{I}}\right)[40,41]$ :

$$
\text { Mass change }=\frac{M_{D}-M_{I}}{M_{I}} \times 100 \%
$$

\subsubsection{Tensile testing}

To improve the confidence in using AM parts for biomedical applications, specimens were mechanically tested in an environment close to in vivo, i.e. submerged at $37^{\circ} \mathrm{C}$ using an Instron 5944 equipped with BioPlus Bath system containing temperature-controlled bath (Instron BioPlus, Instron, USA). In our previous study [33], the importance of submerged testing for mechanical properties of 3D-printed PLA was highlighted: there is potential for two-fold overestimation of mechanical properties when testing in open-air laboratory conditions. Specimens were subjected to uniaxial tension at a constant displacement rate of $0.5 \mathrm{~mm} \cdot \mathrm{min}^{-1}\left(4 \times 10^{-4} \mathrm{~s}^{-1}\right.$ strain rate) using a $2 \mathrm{kN}$ load cell. The effect of load-cell sensitivity on the measurements was checked by repeating tests for $\mathrm{F}$ specimen with a $500 \mathrm{~N}$ load cell: the mean value of strength was within $3 \%$ of the value obtained for the $2 \mathrm{kN}$ load cell $(<1 \mathrm{MPa}$ difference), i.e. withing a natural scatter band, while minimal and maximal values for five specimens were similar for the two load cells. Dried specimens were placed in the bath for 30 mins prior to the start of the test to achieve uniform temperature and water absorption [33]. For strength calculation, the pre-fracture area was measured using a Zeiss Primotech optical microscope at $5 x$ magnification. For $Z$ specimens, the mean bond width (based on 10 measurements for each specimen) was used to calculate a cross-sectional area. For $F$ specimens, the total cross-sectional area of filaments was measured [33]. The mean mechanical properties for each time interval were calculated from ten replicates. The linear region of each stress strain curve was used to measure the tensile modulus for each specimen. The mean toughness value (the ability of material to absorb energy during deformation) was also calculated using the area underneath the stress-strain curves.

\subsubsection{Differential scanning calorimetry}

The thermal properties of specimens $(n=2)$ were examined before and after degradation using a TQ2000 (TA, instrument, USA) Differential Scanning Calorimetry (DSC) system. Sections of dried specimen from the gauge were cut and loaded onto the aluminium pans (weight of 6-10 
$\mathrm{mg}$ ). Thermal analysis was carried out using heating cycles from 20 to $200^{\circ} \mathrm{C}$ at a ramping rate of $10^{\circ} \mathrm{C} \cdot \mathrm{min}^{-1}$ and a nitrogen flow rate of $50 \mathrm{ml} \cdot \mathrm{min}^{-1}$. The obtained thermograms were analysed using TA Universal software to determine $T_{g}, T_{m}$ and cold crystallisation temperature $\left(T_{c c}\right)$. The average degree of crystallinity $\left(X_{c} \%\right)$ was calculated from two measurements for $Z$ and $\mathrm{F}$ :

$$
X_{c}=\frac{\Delta H_{m}-\Delta H_{c c}}{\Delta H^{0}{ }_{m}} \times 100 \%
$$

where $\Delta \mathrm{H}_{\mathrm{m}}, \Delta \mathrm{H}_{\mathrm{cc}}$ and $\Delta \mathrm{H}^{0}{ }_{\mathrm{m}}$ are melting enthalpy $\left(\mathrm{J} . \mathrm{g}^{-1}\right)$, cold crystallisation enthalpy $\left(\mathrm{J} . \mathrm{g}^{-1}\right)$ and enthalpy of fusion for $100 \%$ crystalline PLA, which is $93.1 \mathrm{J.g}^{-1}[33,42]$.

\subsubsection{Gel permeation chromatography}

The molecular weight of $Z$ and $F$ specimens were monitored by measuring the $M_{w}$ and $M_{n}$ values using a gel permeation chromatography (GPC) system (Infinity 1260, Agilent Technologies). A section of gauge region was dissolved in $\mathrm{CHCl}_{3}+2 \%$ triethylamine at a concentration of $1 \mathrm{mg} \cdot \mathrm{ml}^{-1}$. The GPC solutions were left to dissolve for 48 hours. A syringe containing $0.22 \mu \mathrm{m}$ needle filter was used to transfer the solution into a GPC vial. The GPC was performed on two replicates using a $100 \mu$ injection volume at a flow rate of $1 \mathrm{ml} \cdot \mathrm{min}^{-1}$ with a refractive index $(\mathrm{RI})$ detector at $40^{\circ} \mathrm{C}$ using two Plgel mixed $\mathrm{C}$ columns. The data were analysed to calculate the mean $M_{w}$ and $M_{n}$ using Cirrus SEC software against the polystyrene standards $[43,44]$. Once GPC data were collected, the Arrhenius equation was used to characterise the effect of degradation temperature on the reaction rate from the molecular weight data $[44,45]$ :

$$
k=A e^{-E A / R T}
$$

where $k$ is the reaction rate, $\mathrm{A}$ is a constant, $\mathrm{E}_{\mathrm{A}}$ is the activation energy $\left(\mathrm{kJ}_{\mathrm{mol}}{ }^{-1}\right), \mathrm{R}$ is the universal gas constant $\left(\mathrm{J} . \mathrm{K}^{-1} \cdot \mathrm{mol}^{-1}\right)$ and $\mathrm{T}$ is the temperature in Kelvin $[44,45]$. The Arrhenius equation is suitable if a linear relationship between $\ln k$ and $1 / T$ exists, therefore, Equation 4 can be simplified.

$$
\ln k=-\left(\frac{E_{A}}{R}\right)\left(\frac{1}{T}\right)+\ln A
$$

\subsubsection{Fourier transform infrared spectroscopy}

Infrared spectra of undegraded and degraded specimens were recorded using an attenuated total reflectance (ATR) mode of a Fourier transform infrared spectroscopy (FTIR) instrument (Nicolet 6700, Thermo-Scientific, UK). The spectra were collected in the range of 400 to 4000 $\mathrm{cm}^{-1}$ at a resolution of $2 \mathrm{~cm}^{-1}$ by averaging 64 scans. The spectra were baseline corrected and normalised to the peak at $1455 \mathrm{~cm}^{-1}$ corresponding to the $\mathrm{C}-\mathrm{H}$ deformation for $\mathrm{CH}_{2}$ group $[46,47]$. The carbonyl absorption between $1600-1800 \mathrm{~cm}^{-1}$ was subjected to curve fitting using 
Originlab software employing a Gaussian function according to [46]. The peak-to-height ratio (PHR) for various bands $\left(\mathrm{H}_{\text {peak }}\right)$ was quantified using the reference peak at $1455 \mathrm{~cm}^{-1}$ as explained in study [46] to monitor the degradation process:

$$
P H R=\frac{H_{\text {peak }}}{H_{\text {Ref peak }\left(1455 \mathrm{~cm}^{-1}\right)}} \times 100 \%
$$

\subsubsection{Optical microscopy}

The fracture surface of each specimen was examined using a Zeiss Primotech optical microscope at $5 x$ magnification.

\section{Results and discussion}

This section is divided into four main sections:

- 3.1 - Discussing the limited effect of physical ageing on the mechanical and thermal properties of $Z$ and $F$ specimens.

- 3.2 - Considering hydrolytic degradation of PLA by tracking the water absorption for both $Z$ and $F$ specimens to check the dependency of PLA on degradation temperature. The mechanical degradation of interface ( $Z$ specimen) at different temperatures was compared against that of the bulk material, accompanied by assessing the thermal properties and structural changes to explain the trends observed for mechanical properties.

- 3.3 - Relating the mechanical and thermal properties to $M_{n}$ data to determine threshold $M_{n}$ for a 3D-printed part before losing its mechanical integrity. The suitability of accelerated tests to predict the long-term effect of degradation on PLA properties was also assessed.

- 3.4 - Comparing the fracture surface of $Z$ and $F$ specimens to explain the features observed during degradation.

The overall layout of this section is demonstrated in Figure 2. First, effects of physical ageing in air at room temperature on mechanical and thermal properties were considered. Subsequently, the effect of moisture absorption on physical properties of the polymer was examined. Then, the temporal changes in mechanical properties during degradation at three temperatures in media were evaluated and linked with various material/microstructural properties (i.e. crystallinity, FTIR spectra peaks and molecular weight). Finally, fracture surfaces of both $F$ and $Z$ specimens revealed a transition from ductile to brittle fracture mechanisms during degradation, linked to the polymer microstructure. 


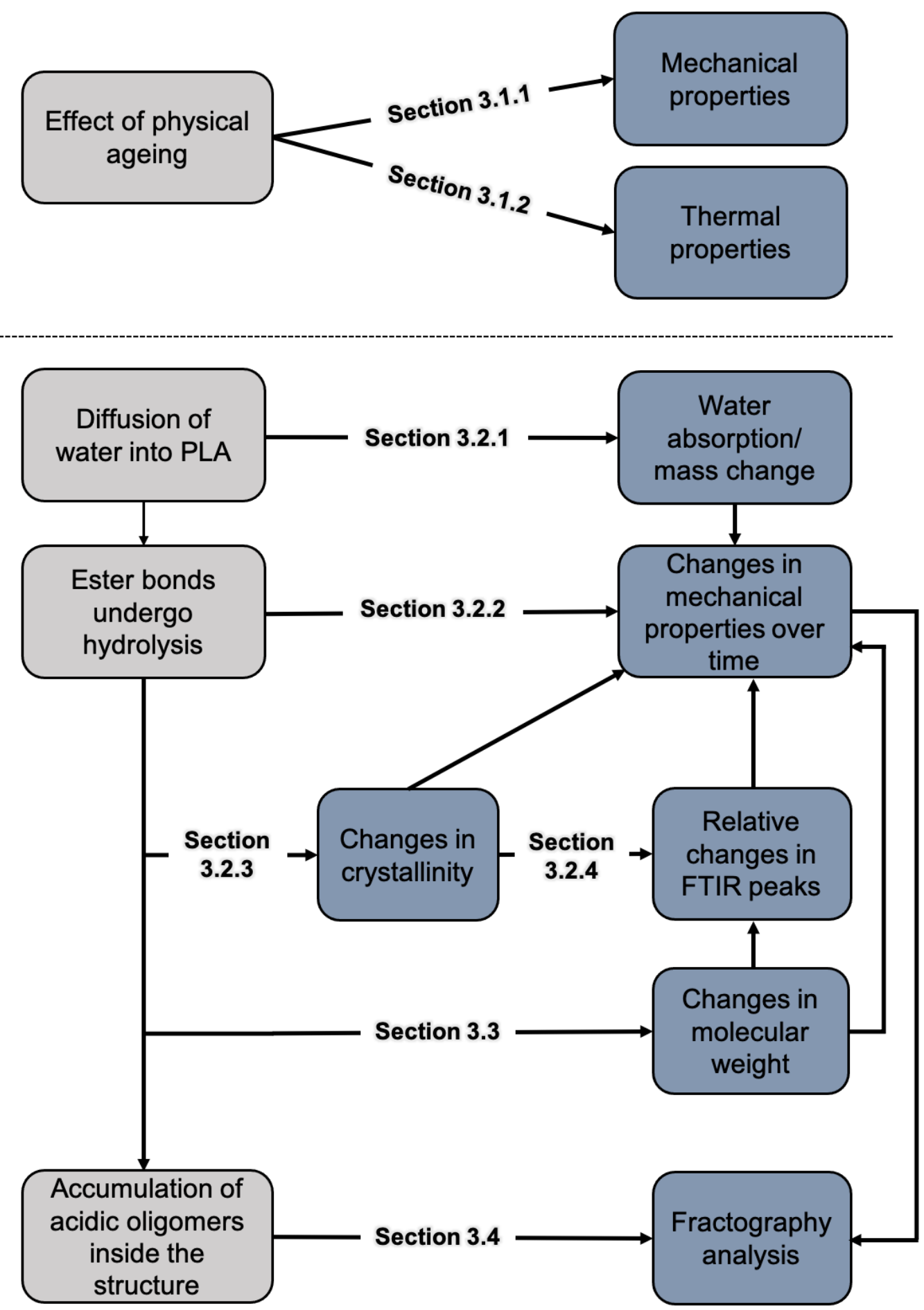

Figure 2 Flowchart of results and discussion section. 


\subsection{Physical ageing of polymer}

PLA can undergo both physical ageing and hydrolytic degradation. It is therefore important to study these two phenomena separately to gain a fundamental understanding of the degradation of 3D-printed parts and, more specifically, the degradation of interface.

\subsubsection{Mechanical properties during ageing}

The obtained results demonstrated that, for undegraded $Z$ and $F$ specimens, the mean tensile strength values for submerged testing at $37^{\circ} \mathrm{C}$ (Figure $3 a$ ) were $27.5 \mathrm{MPa}$ and $33.1 \mathrm{MPa}$, respectively, with a difference of just $5.6 \mathrm{MPa}$. After 300 days of physical ageing at RT, the mean values were 27.6 and $33.4 \mathrm{MPa}$ for $Z$ and $\mathrm{F}$ specimens, respectively. The tensile modulus (Figure $3 \mathrm{~b}$ ) also showed little change $(<5 \%)$. Similar findings were observed for strain at maximum force (Figure 3c), strain at break (Figure 3d) and toughness (Figure 3e). Such results indicated that the degradation of PLA at laboratory conditions (i.e. in air at RT) had a negligible effect on the mechanical properties of PLA (tensile tested submerged at $37^{\circ} \mathrm{C}$ ). Despite having comparable strength values, the strain at break and toughness were significantly different for $Z$ and $F$ due to strain localisation in the interface bond, which caused a sudden and brittle fracture similar to previous studies [19,33]. Meanwhile, F specimens represented bulk behaviour and did not failure up to $40 \%$ strain (as shown by arrows). The prolonged plasticity compared to typical values occurred due to the synergistic effect of water and temperature surrounding the material during tensile testing under physiological conditions [33]. These results agreed well with study [36], which showed no change in mechanical properties of injection-moulded PLA after 360 days of ageing. Visual examination of the specimens (Figure $3 \mathrm{f}$ ) also demonstrated no changes in appearance of the specimens up to 300 days. 


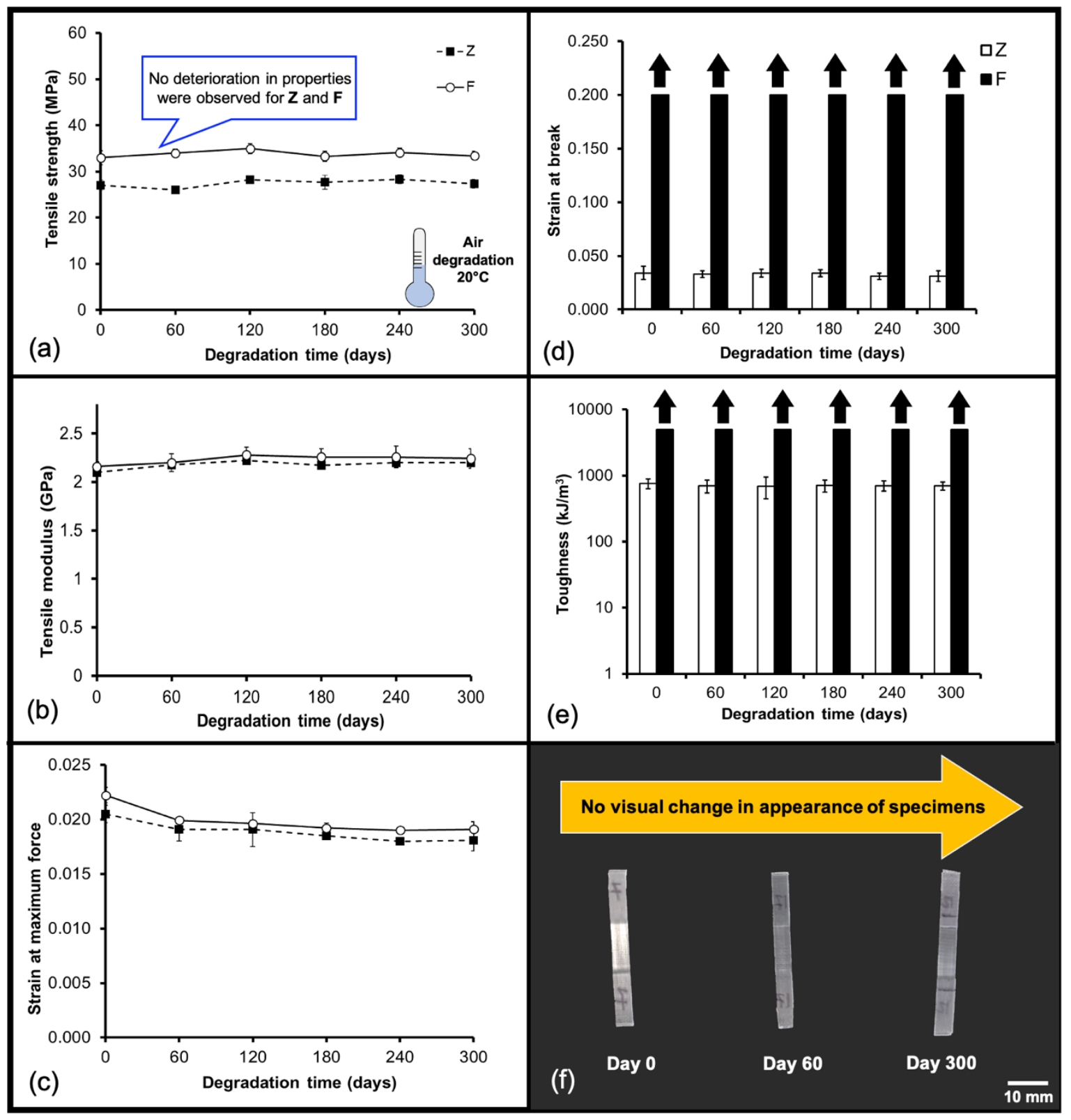

Figure 3 Tensile strength (a), tensile modulus (b), strain at maximum force (c), strain at break $(d)$, toughness (e) and images ( $f$ ) of air-degraded specimens at different times. Both $Z$ and $F$ specimens showed no degradation of properties. None of the $F$ specimens failed up to strain $40 \%$ (denoted by the arrows). The images also demonstrated no visual changes in appearance in contrast to hydrolytic degradation (see Figure 7). Error bars indicate standard deviation.

\subsubsection{Thermal properties during ageing}

The thermal properties of undegraded and aged specimens were also measured (Figure 4). The values for $T_{g}$ (Figure $4 a$ ) and $T_{m}$ (Figure $4 b$ ) were similar to those at day 0 , confirming the slow ageing of PLA and supporting the results for mechanical properties (Figure 3). The crystallinity value $(\approx 3 \%$ ) (Figure $4 \mathrm{c}$ ) stayed unchanged and, therefore, there was no change 
in $T_{g}$ and $T_{m}$. Studies presented conflicting results for the effect of physical ageing on these two temperatures. Some studies $[37,48,49]$ reported that ageing was accompanied by increased $T_{g}$, whilst others [35] stated the opposite. The physical ageing is normally discussed in terms of the enthalpy relaxation- i.e. an endotherm peak at $T_{g}$ which increases in intensity with ageing-. The obtained results (data not shown) revealed no general trend, further confirming no rearrangement of polymer chains and no ageing of PLA. The results clearly indicated that physical ageing had a limited effect on properties of PLA and, therefore, in the next section, the effect of hydrolysis on PLA is discussed.
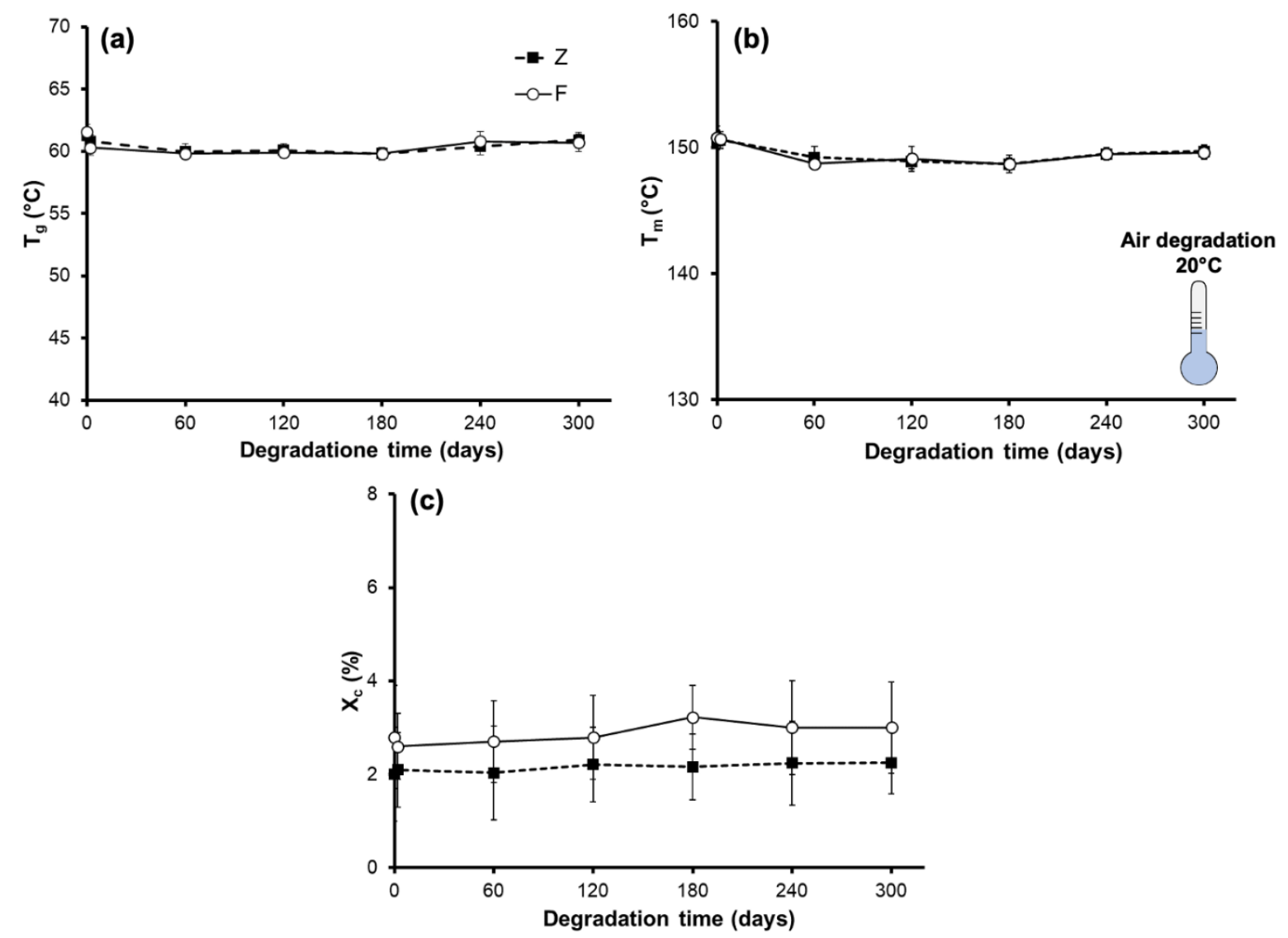

Figure 4 Evolution of $T_{g}(a), T_{m}(b)$ and crystallinity $\left(X_{c}\right)$ (c) for $Z$ and $F$ specimens. Physical ageing was minimum since there was no significant change in thermal properties. Moreover, no considerable difference between $Z$ and $F$ was found.

\subsection{Hydrolytic degradation}

This section discusses the hydrolytic degradation of $Z$ and $F$ specimens. The first part covers water absorption and mass change for different degradation temperatures to study the viability of accelerated temperature for prediction of polymer behaviour in terms of water uptake. After that, degradation of mechanical properties over time is analysed and linked to thermal and chemical properties of $Z$ and $F$ specimens. 


\subsubsection{Water absorption study}

The results presented in Figures $5 a$ and $b$ show the extent of water absorption and dry-mass change, respectively, for both $\mathrm{F}$ and $\mathrm{Z}$ specimens degraded at different temperatures. To allow direct comparison of data, time was normalised by the time to halve $\mathrm{M}_{\mathrm{w}}\left(\mathrm{t}_{0.5 \mathrm{Mw}}\right)$. No noticeable differences were found between $F$ and $Z$ specimens throughout the degradation an an temperature. The plot for water absorption can be divided into two main regions: (i) saturation, and gradual and small increase, before (ii) the sudden increase in water absorption due to degradation, which coincided with a decrease in dry mass.

At $37^{\circ} \mathrm{C}$, polymer saturation $(0.761 \%$ water absorption) happened within 2 hours, which then levelled off until a normalised time of 2. Degradation at accelerated temperatures allowed a greater amount of immediate water uptake, $1.17 \%$ and $1.23 \%$ for $50^{\circ} \mathrm{C}$ and $65^{\circ} \mathrm{C}$, respectively, due to the increase in chain mobility at temperatures closer to $T_{g}$ of PLA ( $\approx 63^{\circ} \mathrm{C}$ ) [45]. In the later stage of degradation, all specimens showed a sudden increase in water absorption after a normalised time of between 3 and 4 .

When $M_{w}$ was low enough to allow diffusion of soluble monomers out of bulk structure, mass change dominated this process [50]. The change in dry mass was more noticeable for 50 and $65^{\circ} \mathrm{C}$ compared to $37^{\circ} \mathrm{C}$. Overall, results obtained in this study were in agreement with previous works $[45,51,52]$ suggesting there is a time-lag before observing a significant mass change. 

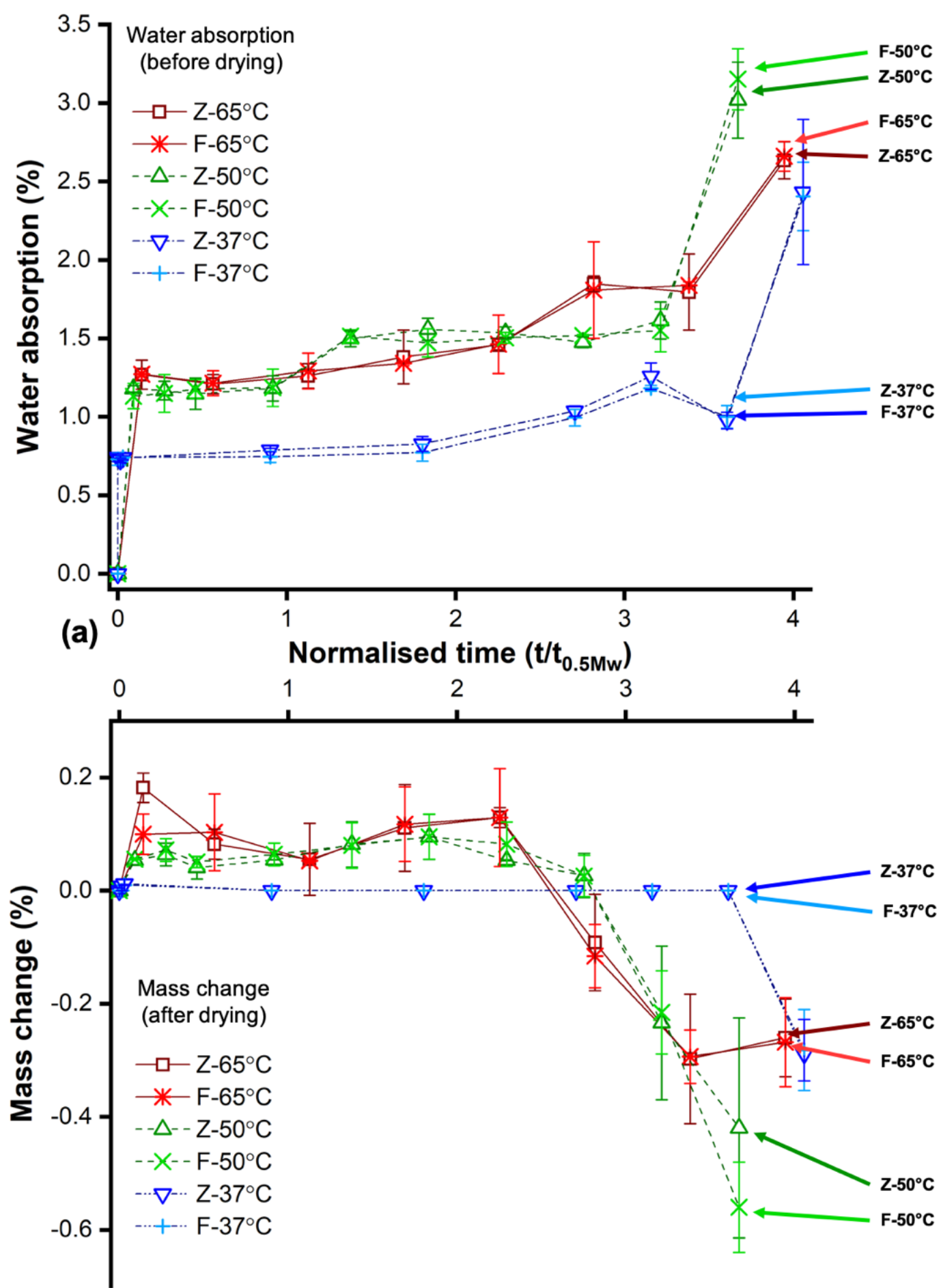

(b)

Figure 5 Evolution of mean water absorption (a) and mass change (b) for $Z$ and $F$ specimens degraded at different temperatures showed no significant difference. Accelerated tests allowed greater amounts of water uptake until $M_{w}$ was low enough to permit diffusion of soluble monomers, which coincided with a change in dry mass. Error bars indicate standard deviation.

Visual examination of specimens at different stages of degradation (Figure 6) showed that undegraded specimens were initially transparent (stage 1), but when degradation started, 
specimens became brittle and also changed colour to white (stage 2). At the final stage of degradation (stage 3), due to extensive chain scissions, brittleness increased causing disintegration into pieces without mechanical integrity. In addition to visual inspection, measurements for mean thickness and width for both $\mathrm{F}$ and $\mathrm{Z}$ specimens degraded at $37^{\circ} \mathrm{C}$ showed little differences during degradation ( $<1 \%$ change in cross-sectional area from day 0 to 240), suggesting bulk degradation of PLA rather than surface erosion.

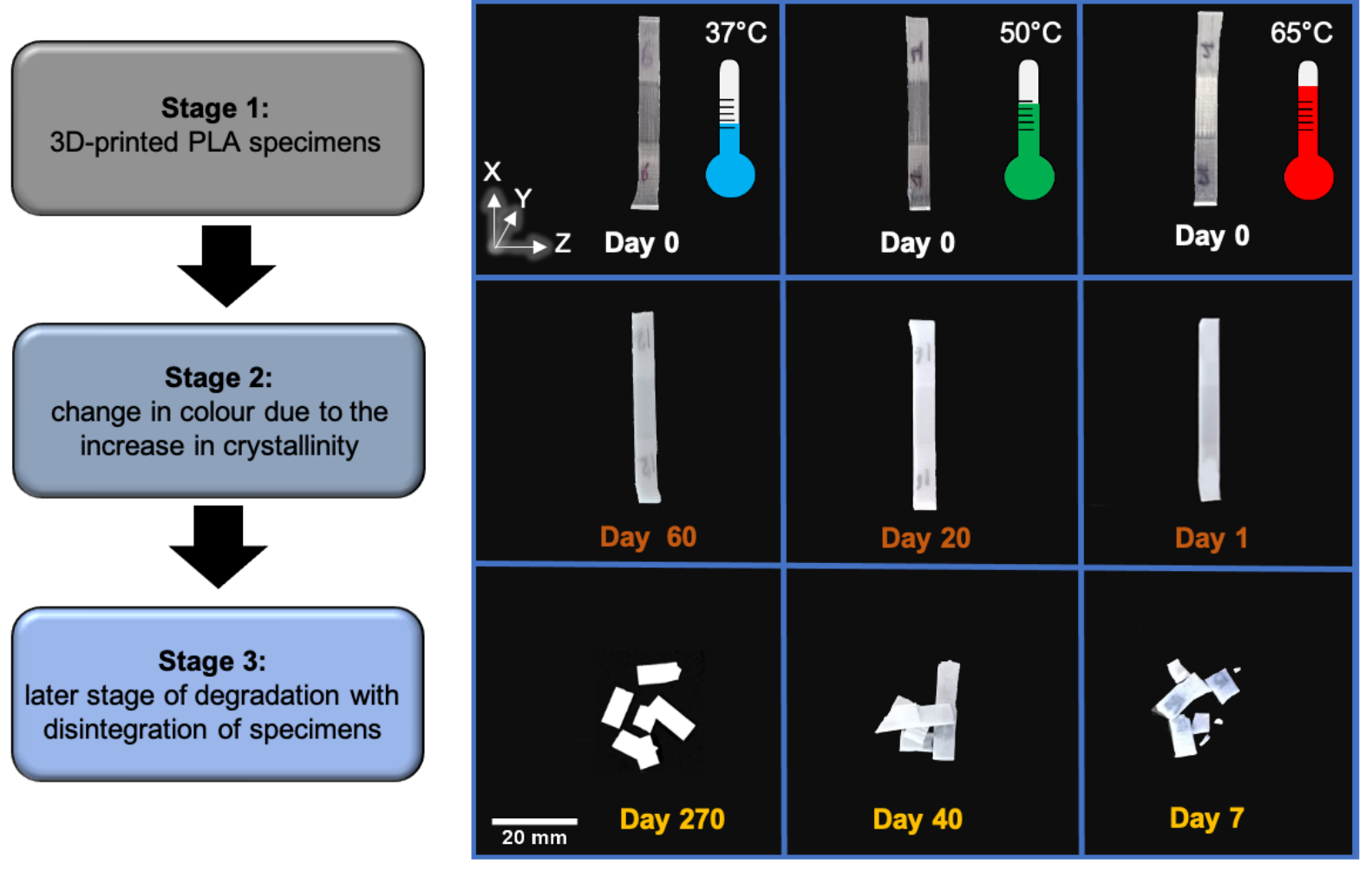

Figure 6 Specimens during different stages of degradation. As degradation continued the transparent specimens (stage 1) turned into white (stage 2). Further degradation of specimens resulted in disintegration of polymer into pieces (stage 3).

\subsubsection{Degradation of mechanical properties}

The mechanical properties of $Z$ and $F$ specimens tested submerged at $37^{\circ} \mathrm{C}$, before and after degradation at different temperatures, are presented in Figure 7 and 8 . $Z$ and $F$ specimens had initial tensile strength values of $27.5 \pm 1.7 \mathrm{MPa}$ and $33.1 \pm 0.9 \mathrm{MPa}$, respectively. The reduction in the strength was detected after some delay for both specimens, suggesting similar behaviours of interface and bulk material. The tensile strength for both testing directions at $65^{\circ} \mathrm{C}$ reduced to zero after 4 days (Figure 7a). Meanwhile, it took 35 and 270 days to reach zero strength at $50^{\circ} \mathrm{C}$ (Figure $7 \mathrm{~b}$ ) and $37^{\circ} \mathrm{C}$ (Figure $7 \mathrm{c}$ ), respectively. At the end, specimens were brittle and could not be gripped, indicating the extensive degradation of the PLA. 
The delay period was the shortest for the accelerated tests suggesting the higher rate of degradation. Some improvement in strength was observed during early stages of degradation, which is discussed in Section 3.2.3 in relation to crystallinity. Strength increased by $33.3 \%$ regardless of testing direction after only 1 day of degradation at $65^{\circ} \mathrm{C}$ (Figure 7a). At $50^{\circ} \mathrm{C}$, the strength improved only by $12.2 \%$ on average for both $Z$ and $F$ specimens after 1 day (Figure $7 \mathrm{~b})$. Specimens degraded at $37^{\circ} \mathrm{C}$ had the least improvement in strength only $5 \%$ after 60 days (Figure 7c).

A long induction period was found before the tensile modulus dropped to zero for all three temperatures for both types of specimens. Regardless of degradation temperature, the changes in tensile modulus of $Z$ specimens were comparable to that of bulk material throughout the degradation. The data for strain at maximum force showed that for both testing directions, the material became more brittle during degradation. This could be a result of a combination of changes in crystallinity and $M_{w}$ which is explained in the next sections.

Although $Z$ and $F$ specimens demonstrated similar strength and modulus values, the strain at break (Figure 8a, b and $c$ ) and toughness (Figure 8b, $d$ and e) differed by an order of magnitude before degradation. The strain localisation at the interface for $Z$ specimens was responsible for brittle fracture as explained in a recent study [19] using this specimen design. However, these two properties were the most sensitive ones to degradation even at the early stage. This is because both properties are drastically altered by any changes in both macroscopic (e.g. surface defect) and materials features (e.g. $M_{w}$ and crystallinity) as the result of degradation. This was obvious for $F$ specimens, since the undegraded specimens did not fail up to 0.4 strain, while after only 1 day of degradation at $65^{\circ} \mathrm{C}$, the strain at break reduced to only 0.052 . Although $Z$ specimens were brittle before degradation (strain at break of 0.034), degradation lowered the value but to a lesser degree than $F$ specimens. As degradation continued, both $\mathrm{Z}$ and $\mathrm{F}$ specimens started to behave similarly and demonstrated a very close levels of strain at break of 0.005 at the end of degradation for all degradation temperatures. F specimens had much higher toughness values thanks to orientation of filaments along the testing direction by absorbing more energy before failure. Similar to other properties, toughness of both $Z$ and $F$ approached a similar value at the later stages of degradation. The gradual convergence of these properties indicates that (degrading) mechanical properties of the bulk material gradually became a more dominant factor than inherent anisotropy due to the printing process and extruded-filament geometry. 


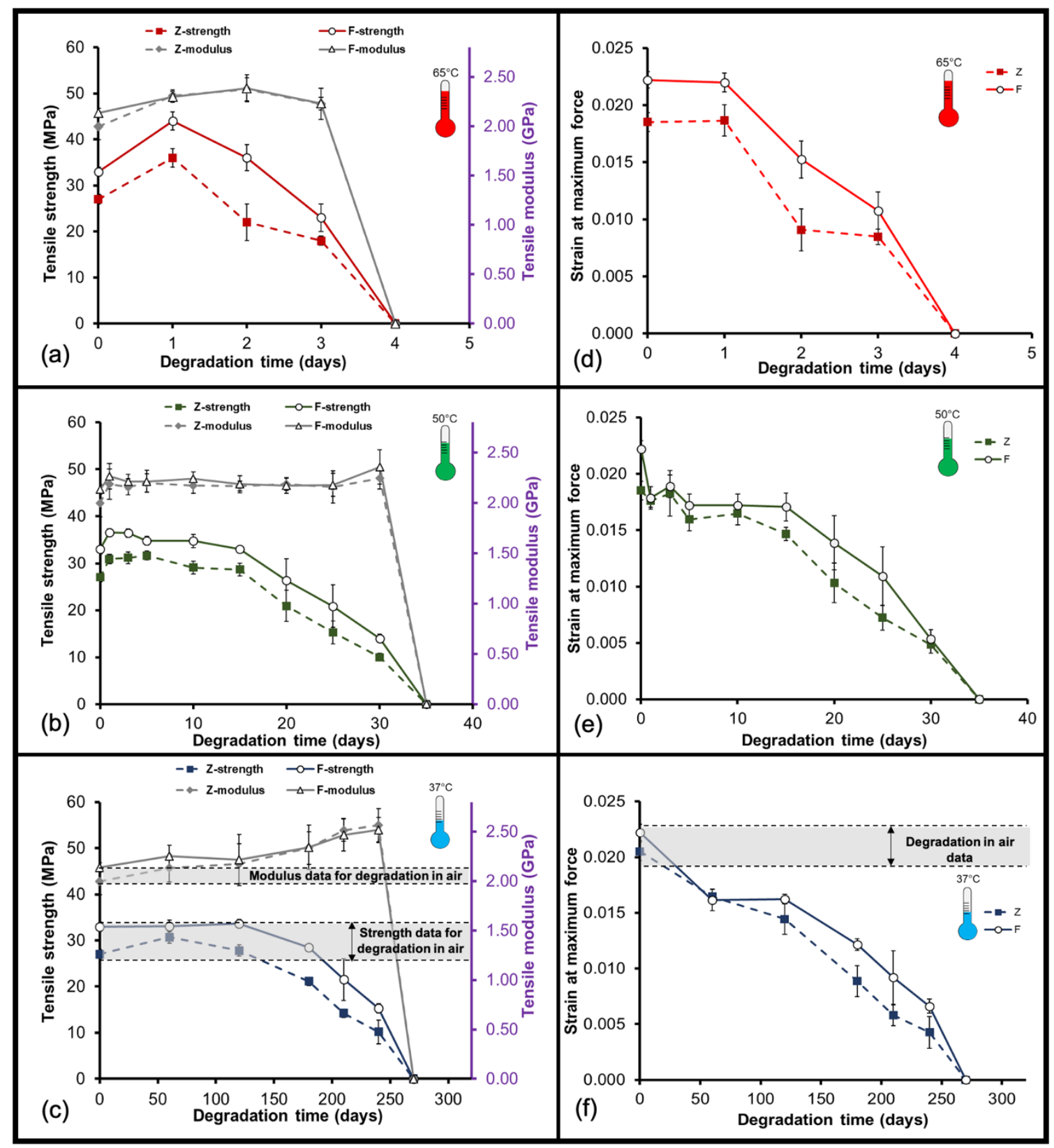

Figure 7 Degradation of mean tensile strength and modulus at $65^{\circ} \mathrm{C}(\mathrm{a}), 50^{\circ} \mathrm{C}(\mathrm{b})$ and $37^{\circ} \mathrm{C}$ (c) indicated that the rates of decrease for both $Z$ (dashed line) and $F$ (solid line) were similar. The strain at maximum force for $Z$ and $F$ specimens degraded at $65^{\circ} \mathrm{C}(d), 50^{\circ} \mathrm{C}(e)$ and $37^{\circ} \mathrm{C}$ (f) showed a similar trend to strength data over the course of degradation. Grey shaded regions represent the degradation in air data (see Figure 3). Error bars indicate standard deviation. 


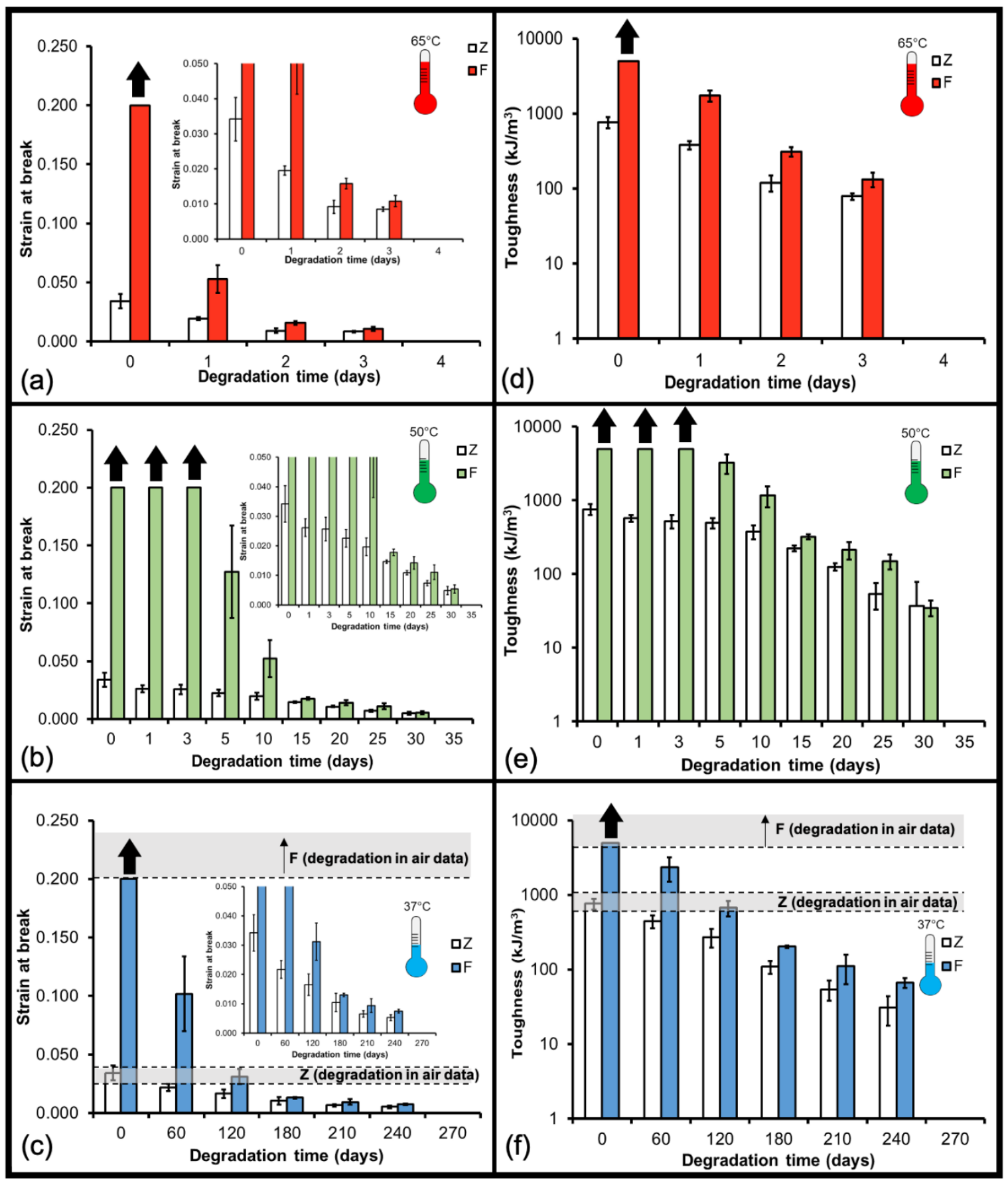

Figure 8 The reduction in strain at break at $65^{\circ} \mathrm{C}(\mathrm{a}), 50^{\circ} \mathrm{C}(\mathrm{b})$ and $37^{\circ} \mathrm{C}(\mathrm{c})$ indicated multiplefold initial anisotropy between $F$ (solid-bar column) and $Z$ (empty-bar columns) specimens, which converged as material degraded. A similar trend was observed for toughness for both directions degraded at $65^{\circ} \mathrm{C}(d), 50^{\circ} \mathrm{C}(e)$ and $37^{\circ} \mathrm{C}(f)$. Grey shaded regions represent the degradation in air at RT for both $Z$ and $F$ specimens which showed no noticeable changes in properties over 300 days. Arrows above bars indicate the specimens that did not fracture at $40 \%$ strain. Error bars indicate standard deviation. 
The suitability of using accelerated degradation tests was examined. To do this, all data were normalised by their initial values for strength $\left(\sigma / \sigma_{0}\right)$, strain at maximum force $\left(\varepsilon_{\text {max.force }} / \varepsilon_{\text {max.force } 0}\right)$ and modulus $\left(\mathrm{E} / \mathrm{E}_{0}\right)$. Whereas, strain at break $\left(\varepsilon_{\text {break }}\right)$ and toughness $(\mathrm{G})$ were normalised against the values for the normalised time of 0.5 since the initial values were not measurable (F specimens did not fail). From Figure 9, it is clear that degradation of the interface was similar to that of the bulk material. Furthermore, similar trends were observed at all temperatures, indicating that accelerated tests can be used for prediction of longer-term performance at $37^{\circ} \mathrm{C}$. The current study used a novel specimen design and manufacturing approach to eliminate thermal variation and design complexity for ASTM standards during the printing process. The results are valuable for designing new medical implants when timedependent properties of 3D-printed polymer during its degradation are critical. They also give confidence in using AM parts for biomedical applications as long as they have suitable initial mechanical properties, since the interface between layers was found to degrade in a similar manner to the bulk polymer. 

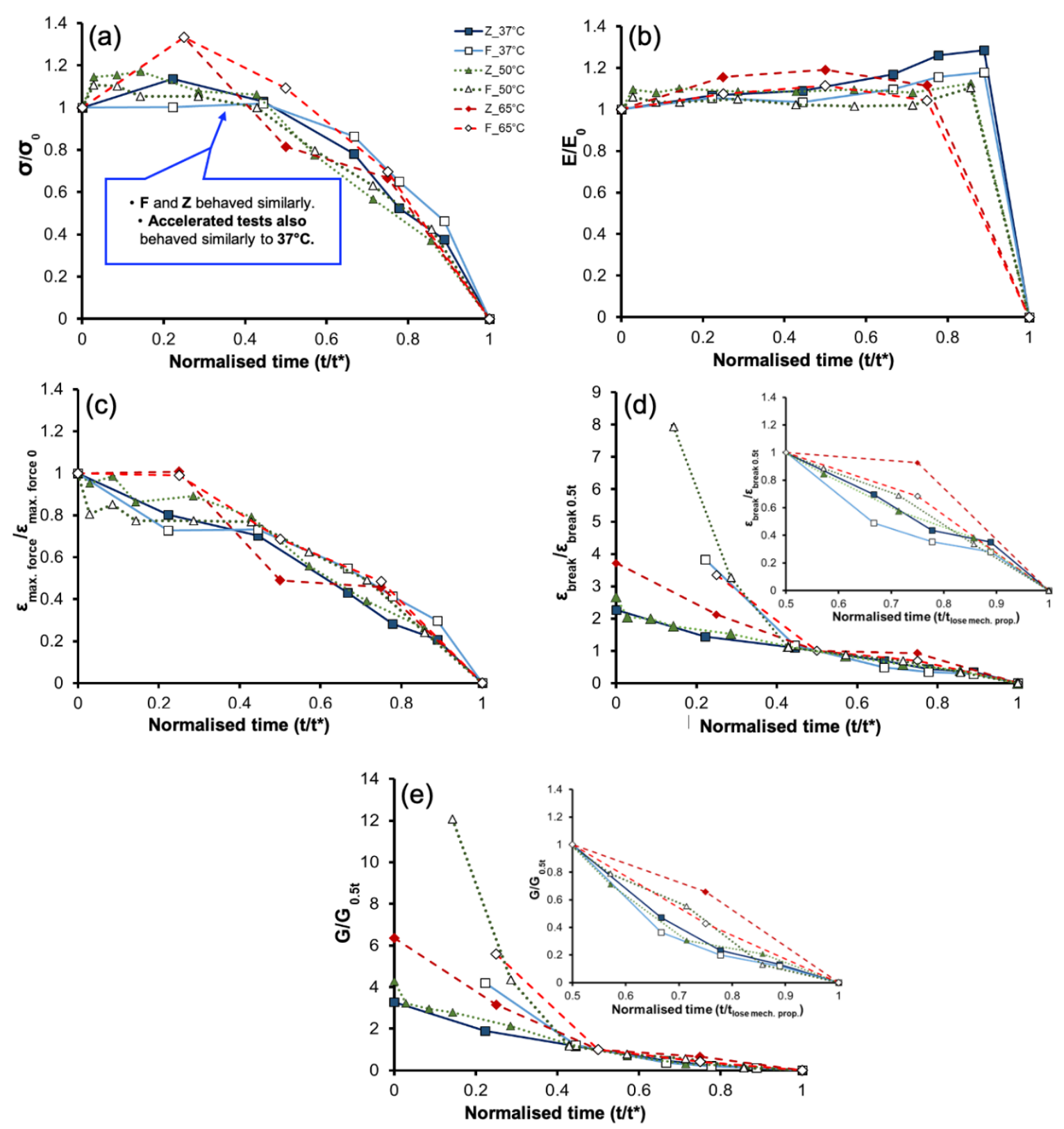

Figure 9 Evolution of normalised tensile strength (a), tensile modulus (b), strain at maximum force (c), strain at break (d) and toughness (e) indicating similar changes in properties for $Z$ and $F$. Accelerated temperatures can be used to predict mechanical properties of 3D-printed PLA. Data for strain at break and toughness were normalised by the time 0.5 as opposed to initial properties since $F$ specimens did not fail at time 0 . ( $t^{*}$ is the time to lose mechanical properties).

\subsubsection{Interplay between degradation and crystallisation}

The DSC thermograms of $Z$ specimens at three temperatures are presented in Figure 10 ( $F$ specimens are not shown because they were almost identical to $Z$, as expected). The evolution of $T_{g}, T_{m}$ and crystallinity for both $Z$ and $F$ specimens, normalised by $t_{0.5 \mathrm{Mw}}$, is also 
shown (Figures 10d, e and f). The results can be discussed in terms of (i) the effect of testing direction and (ii) the degradation temperature. No significant difference in thermal properties were found for $Z$ and $F$ directions, supporting the mechanical-properties results (Figure 9). The $\mathrm{T}_{\mathrm{g}}$ graph peaked around $63^{\circ} \mathrm{C}$. Cold crystallisation peak was identified around $110^{\circ} \mathrm{C}$ followed by $T_{m 1}$ of $152^{\circ} \mathrm{C}$. Once degradation started, a second melting peak $\left(T_{m 2}\right)$ around $145^{\circ} \mathrm{C}$ was observed similar to previous studies [53,54] due to the presence of different $\alpha$ homocrystals. The high-temperature melting peak corresponded to the thicker lamellae (i.e. $\alpha$ crystals), whereas, the lower peak represented the imperfect $\alpha^{\prime}$ crystals.

Degradation temperature was an important factor. Both $Z$ and $F$ specimens initially comprised mainly amorphous regions due to low crystallinity values (Figure 10d), and, immediately after degradation, the amorphous regions were subjected to chain scissions and relaxation to form crystalline phases (stage A in Figure 11). This can be seen by the rapid six-fold increase in the crystallinity at $65^{\circ} \mathrm{C}$ (and similar for $50^{\circ}$ ), which increased the strength initially. However, higher crystallinity reduced the strain at break exponentially since stiff crystals cannot elongate in a similar manner to amorphous chains, and instead constrained the chains. This could suggest that during the early-stage of degradation, the change in crystallinity had a greater effect on mechanical properties than reduction of $M_{w}$, in agreement with polymer-chemistry studies for non-additive-manufactured specimens $[10,12,45,55]$. During this stage, there was no obvious changes in $T_{g}$ (Figure 10e) and $T_{m}$ (Figure 10f).

As degradation proceeded, the chain scission and production of oligomers resulted in the substantial decrease in $T_{g}$ and $T_{m}$ due to extensive plasticisation of polymer [6] (stage $B$ in Figure 11). This can be seen since the crystallinity continued to increase to the maximum values of $43.5 \%, 36.7 \%$ and $17.1 \%$ for $65^{\circ} \mathrm{C}, 50^{\circ} \mathrm{C}$ and $37^{\circ} \mathrm{C}$, respectively. This coincided with a reduction in mechanical properties of $Z$ and $F$ specimens, suggesting that a combination of crystallinity and $M_{w}$ reduction were responsible for changes in the mechanical properties of AM parts at the later-stage of degradation, which is discussed in Section 3.3. 

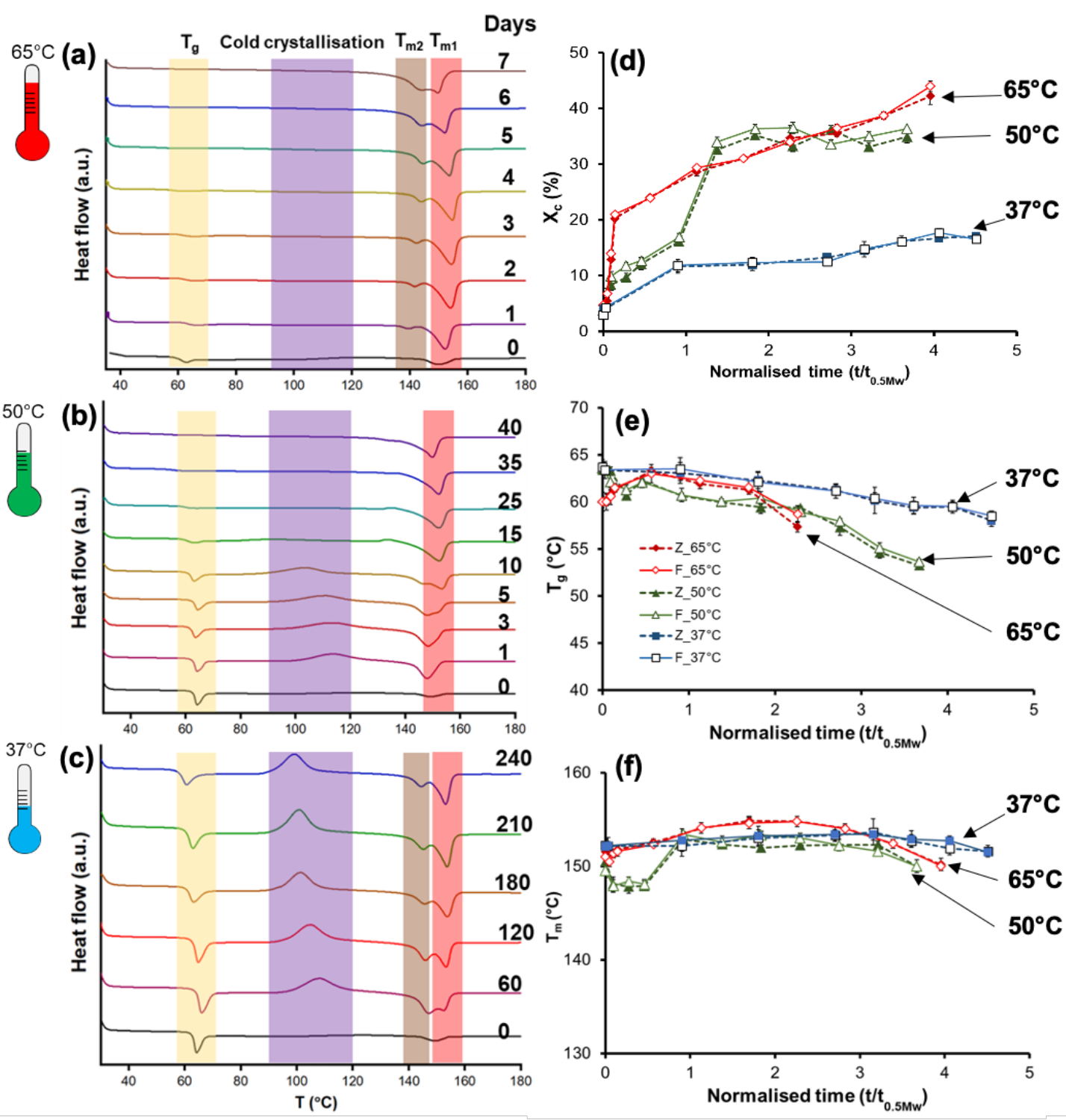

Figure $10 \mathrm{DSC}$ thermograms for $65^{\circ} \mathrm{C}(\mathrm{a}), 50^{\circ} \mathrm{C}$ (b) and $37^{\circ} \mathrm{C}$ (c) showing sensitivity of $P L A$ to the degradation temperature and time. For thermal properties, no difference between $Z$ and $F$ direction was found. (d) A sharp increase in crystallinity was observed especially at higher temperature. (e) $T_{g}$ for both $Z$ and $F$ specimens degraded at different temperatures exhibited a decreasing trend as degradation proceeded. (f) The degradation and plasticising effect of water resulted in the gradual decrease in $T_{m}$ eventually. Error bars indicate standard deviation. 


\section{Hydrolytic degradation}

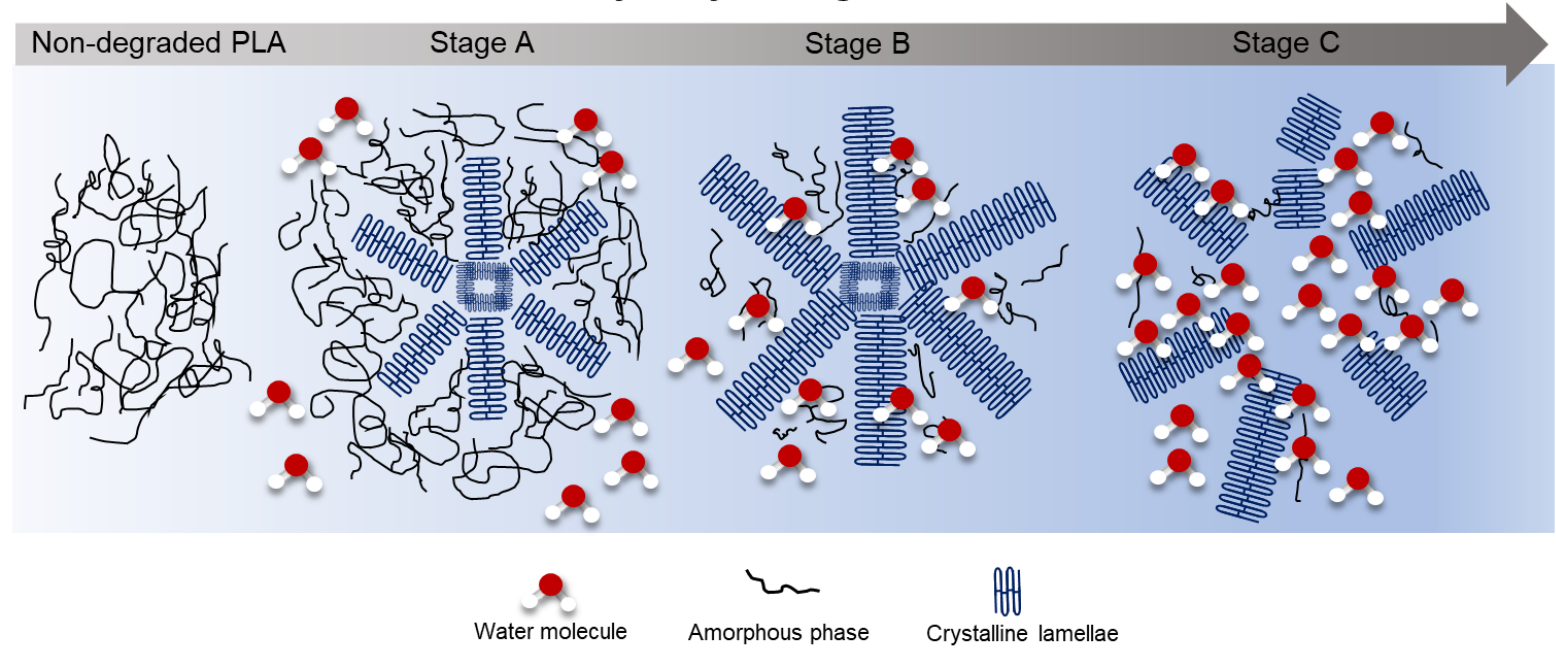

Figure 11 Schematic indicating the hydrolysis of PLA. During stage A chain scissions of amorphous chains allow the formation of crystalline lamella. The formation of crystalline phase continues during stage $B$ as more mobile polymer chains re-organise into crystalline lamella. Finally, at stage $C$, the diminishing amorphous phase between crystalline lamellae becomes degraded to the extent that its mechanical properties are lost.

\subsubsection{Structual changes of polymer chains during degradation}

To support the DSC data, structural changes of $Z$ and F specimens were monitored with FTIR to provide more complementary information. FTIR spectra for degradation of $Z$ and $F$ specimens at $37^{\circ} \mathrm{C}$ only are shown in Figures $12 a$ and $b$, respectively, since all temperatures showed a similar trend. Careful examination of spectra was carried out by curve-fitting of the absorption band at $1755 \mathrm{~cm}^{-1}$, which corresponds to $C=O$ stretching of lactide esters $[46,47]$. The results of curve fitting (deconvolution) of $\mathrm{C}=\mathrm{O}$ peak into three absorption peaks (I-III) are shown in Figures 12c-h. The peak position and resultant area are given in the tables within the figures, with a special focus on peak II as the main one for monitoring degradation. Before degradation, the areas of peak II for $Z$ (Figure 12c) and F (Figure 12d) specimens were 3.02 and 2.11 , respectively. After 240 days of degradation at $37^{\circ} \mathrm{C}$, the values increased to 3.47 (Figure 12g) and 3.30 (Figure 12h), respectively.

The comparison of the areas under the peak once again confirmed similar rates of degradation for the interface bond and bulk material. In addition, a more in-depth analysis of FTIR spectra was done by quantifying the PHR values for $Z$ and $F$ specimens for various bands (Table 2). The absorption band at $920 \mathrm{~cm}^{-1}$ corresponding to the $\alpha$ crystal phase was used to monitor crystallisation dynamics [6]. The PHR value for this band showed a slight fluctuation similar to a previous study [6], with no substantial difference between $Z$ and $F$ specimens; meanwhile, 
the trend was more pronounced for accelerated tests (see Supplementary Data). This trend correlated well with the crystallinity data (Figure 10d).

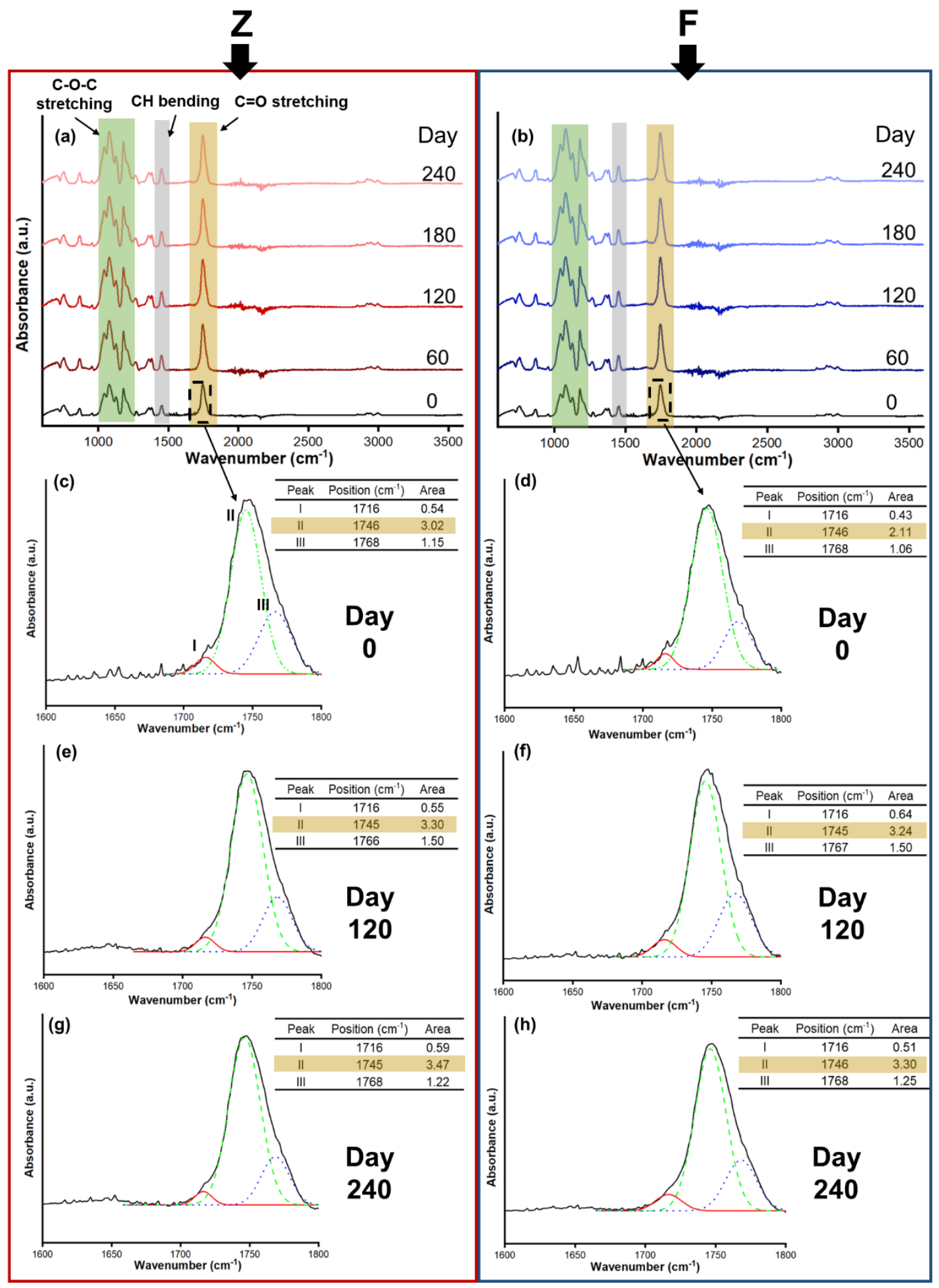

Figure 12 Normalised FTIR spectra obtained for $Z(a)$ and $F(b)$ specimens degraded at $37^{\circ} \mathrm{C}$ indicating that the main absorptions peaks corresponded to lactide esters $\left(1755 \mathrm{~cm}^{-1}\right), \mathrm{C}-\mathrm{H}$ deformation of $\mathrm{CH}_{2}$ groups $\left(1455 \mathrm{~cm}^{-1}\right)$ and $\mathrm{C}-\mathrm{O}-\mathrm{C}$ ether stretching $\left(1150-1060 \mathrm{~cm}^{-1}\right)$. The curve-fitting of the $C=O$ peak components for $Z-0$ day (c), $F$ - 0 day (d), Z- 120 days (e), $F$ 120 days ( $f$ ), $Z-240$ days $(g)$ and $F-240$ days $(h)$ showed an increasing trend for peak II. 
Data for the bands at $1185 \mathrm{~cm}^{-1}$ and $1755 \mathrm{~cm}^{-1}$ were also used to monitor changes in the concentration of ester groups (Table 2). For both bands, the PHR values showed an increasing trend from 0 to 240 days for both testing directions. This trend could be explained by the cleavage of long polymer chains into shorter chains and increasing the formation of new carboxyl end chains as well as new carbonyl compounds [47]. Once more, no significant change was evident for $Z$ and $F$ specimens in terms of PHR values for $1185 \mathrm{~cm}^{-1}$ and 1755 $\mathrm{cm}^{-1}$.

Table 2 Changes in PHR for bands $920 \mathrm{~cm}^{-1}$ (crystallisation dynamics), $1185 \mathrm{~cm}^{-1}$ and 1755 $\mathrm{cm}^{-1}$ for chain scission and degradation. No significant differences were found between $F$ and Z specimens.

\begin{tabular}{|c|c|c|c|c|c|c|c|c|c|}
\hline \multirow{2}{*}{ Degradation time (days) } & \multicolumn{2}{|c|}{ PHR for $920 \mathrm{~cm}^{-1}$} & \multirow{2}{*}{$\Delta \mathrm{PHR}$} & \multicolumn{2}{|c|}{ PHR for $1185 \mathrm{~cm}^{-1}$} & \multirow{2}{*}{$\triangle \mathrm{PHR}$} & \multicolumn{2}{|c|}{ PHR for $1755 \mathrm{~cm}^{-1}$} & \multirow{2}{*}{$\Delta \mathrm{PHR}$} \\
\hline & $Z$ & $F$ & & $Z$ & $F$ & & $Z$ & $F$ & \\
\hline 0 & 0.00 & 0.00 & 0.00 & 2.64 & 2.64 & 0.00 & 2.97 & 3.09 & 0.12 \\
\hline 60 & 0.11 & 0.11 & 0.00 & 2.66 & 2.66 & 0.00 & 3.13 & 3.13 & 0.00 \\
\hline 120 & 0.09 & 0.11 & 0.01 & 2.67 & 2.69 & 0.02 & 3.25 & 3.34 & 0.09 \\
\hline 180 & 0.08 & 0.11 & 0.03 & 2.74 & 2.73 & -0.01 & 3.26 & 3.47 & 0.20 \\
\hline 240 & 0.09 & 0.07 & -0.02 & 2.87 & 2.85 & -0.02 & 3.29 & 3.30 & 0.01 \\
\hline
\end{tabular}

\subsection{Molecular weight degradation}

In this section, degradation of $\mathrm{M}_{\mathrm{w}}$ was considered for both $\mathrm{Z}$ and $\mathrm{F}$ specimens to understand the potential effects of evolution of microstructural changes in PLA on its mechanical properties and degradation kinetics. Such understanding is important to comprehend the complex evolving relationship between mechanical properties and $M_{w}$ for designing new implants.

The GPC curves obtained at different temperatures and time periods were plotted (Figures 13a-c) followed by evolution of normalised $M_{w}$ (Figure 13d) and $M_{n}$ (Figure 13e) for $Z$ and $F$ specimens with normalised time. There was no difference between testing directions once again; therefore, for simplicity, only the GPC curves for $Z$ specimens are shown. The curves shifted to lower values without the formation of any specific peak for crystalline regions. At the same time, the GPC curves for specimens aged in air showed no sign of shifting (grey shaded region in Figure 13a), supporting findings for mechanical and thermal properties in Section 3.1. GPC curves also remained monomodal for all three temperatures in agreement with previous studies $[12,45,55]$. 
The rates of decrease for $M_{w}$ and $M_{n}$ for both $F$ and $Z$ were similar, supporting the earlier results that degradation of the interface happened at the similar rate to that in the bulk material. There was no delay in the reduction of $\mathrm{M}_{\mathrm{w}}$; instead, a large decrease was observed, implying the random scission of long polymer chains $[11,56]$. By the time $M_{w}$ was halved, tensile strength (Figures 7 and 8 ) showed no significant change in values for both $Z$ and $F$ specimens. Once again, this confirmed dependency of early-stage properties on crystallinity (Figure 10d) rather than $M_{w}$ reduction. The tensile strength only started to decrease substantially when $M_{w}$ reduced by more than $50-75 \%$ (see Figures 7 and 8 ).
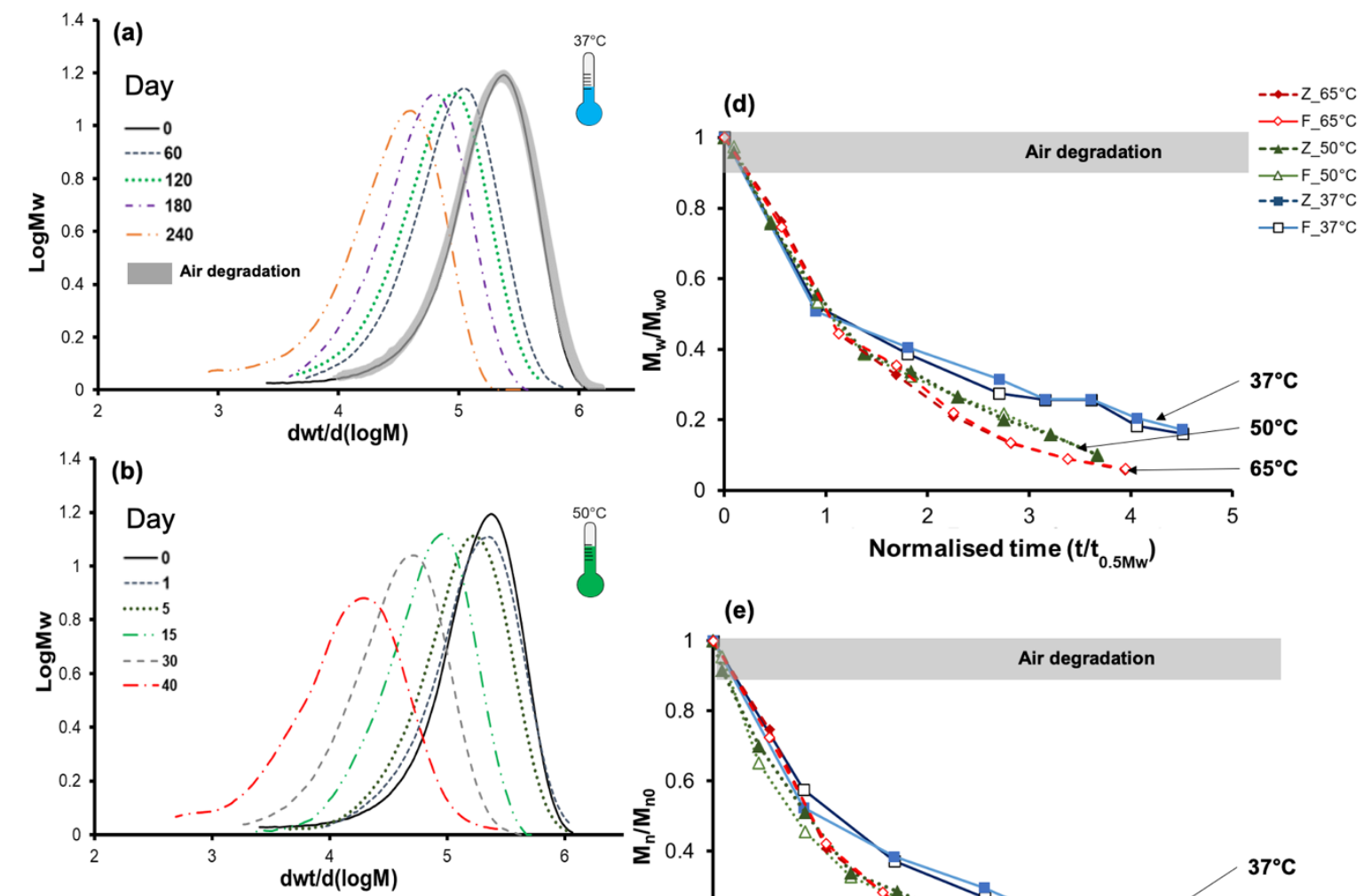

(e)
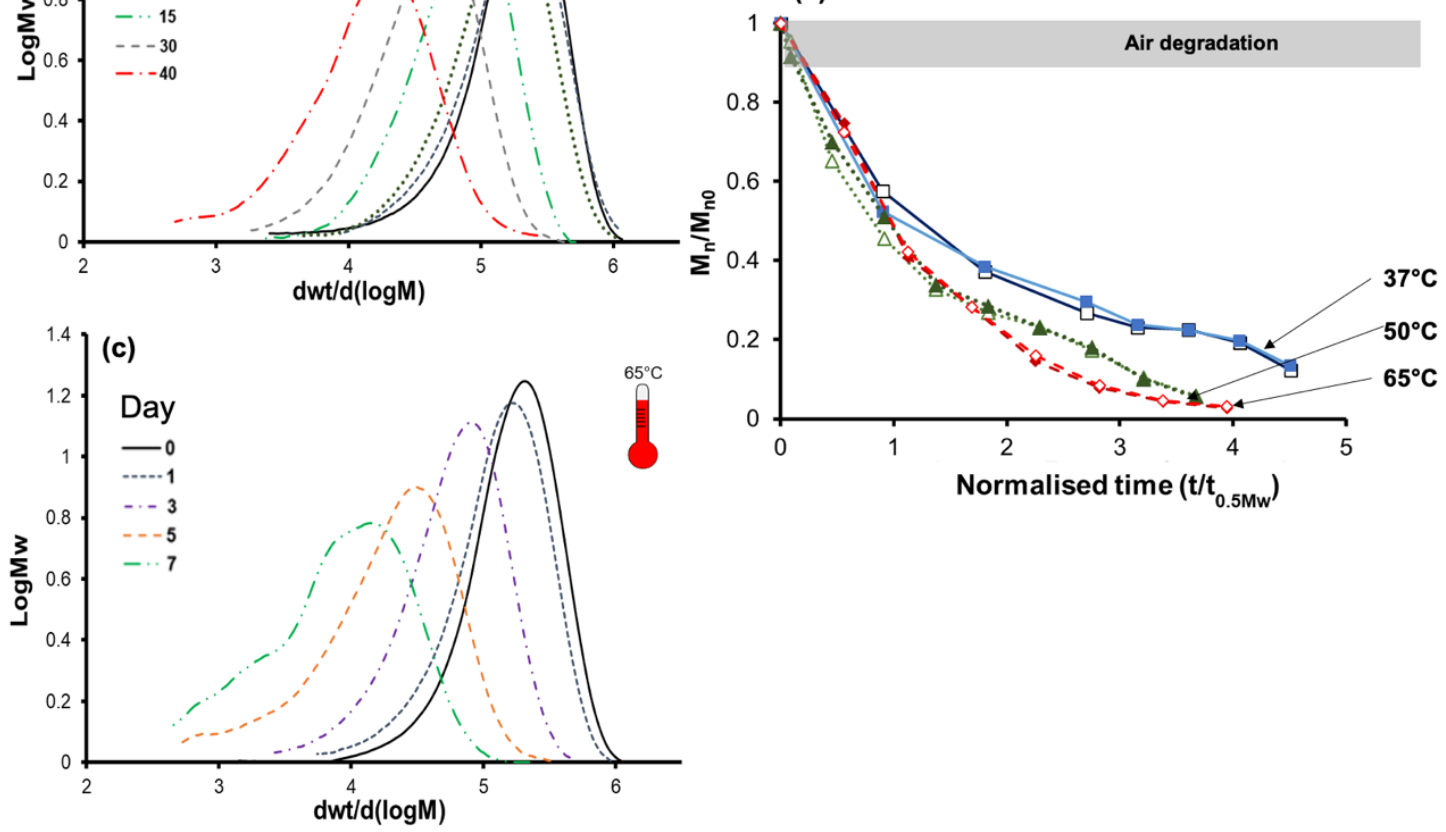

Figure 13 Molecular distribution for PLA for varying time points obtained at different temperatures: (a) $37^{\circ}$; (b) $50^{\circ} \mathrm{C}$; (c) $65^{\circ} \mathrm{C}$. Evolution of normalised $M_{w}$ (d) and $M_{n}$ (e) values for degradation of both $Z$ and $F$ specimens with normalised time for different temperatures showing the similar rates of degradation. In contrast, no general decrease was observed for specimen degraded in air (shaded region). 
The data were examined to determine the mechanism (un-catalysis vs. autocatalysis) of degradation using well-established theories [45]. The plots of molecular weight degradation against hydrolysis time showed a higher $R^{2}$ values for the linear relationship for an autocatalysed model $\left(R^{2}=0.99\right)$ [57]. Additionally, amorphous polymers are known to undergo autocatalytic degradation [12,45,55]. The slopes of $M_{w}$ (Figure 13d) and $M_{n}$ (Figure 13e) for different degradation times were very similar up to normalised time 1 . Beyond that point, the data for $37^{\circ} \mathrm{C}$ showed a lower rate, suggesting a higher rate of autocatalysis degradation at higher temperatures $[57,58]$. This is reasonable since a higher degradation rate allowed less time for catalytic short chains to diffuse out of the polymer, which is discussed shortly in Section 3.4. To check this, a further comparison of rate constants $(k)$ for the autocatalysis model for different testing directions and degradation temperatures was carried out as shown in Table 3. The $k$ constant values were very similar for $Z$ and $\mathrm{F}$ specimens at all temperatures, while, the degradation temperature greatly influenced this value. The rate of hydrolysis increased ten-fold at $50^{\circ} \mathrm{C}$ and eighty-five-fold at $65^{\circ} \mathrm{C}$ compared to $37^{\circ} \mathrm{C}$, confirming that the increase in the slope for $65^{\circ} \mathrm{C}$ after normalised time of 1 corresponds to a higher rate.

Table 3 Calculated hydrolysis rate $k$ at different temperatures.

\begin{tabular}{ccc}
\hline & \multicolumn{2}{c}{$\boldsymbol{k}$ rate for catalysed model } \\
\cline { 2 - 3 } Temperature $\left({ }^{\circ} \mathbf{C}\right)$ & $\mathbf{F}$ & $\mathbf{Z}$ \\
\hline 37 & 0.0060 & 0.0063 \\
50 & 0.0658 & 0.0645 \\
65 & 0.5170 & 0.5371 \\
\hline
\end{tabular}

Some researchers [45] raise concerns about the use of accelerated tests to predict properties of polymer at body temperature. Above the polymer's $T_{g}$, segmental mobility increases and Van der Waals forces holding amorphous phases in place are reduced, facilitating the hydrolysis and higher degradation rates [45]. For this reason, the Arrhenius relationship (Equation 5) was applied to assess the suitability of accelerated tests. A high linear correlation $\left(R^{2}=0.99\right)$ showed that degradation kinetics were not significantly influenced above $T_{g}$, and accelerated tests could be used to understand the degradation profile of polymers with a shorter study duration. From the gradient of the linear relationship (Figure 14a), the activation energy $\left(E_{A}\right)$ was estimated to be $135.6 \mathrm{~kJ} \mathrm{~mol}^{-1}$. Previous studies [44,45,59-61] provided the

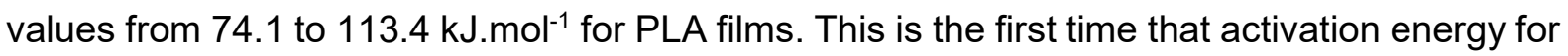
degradation of 3D-printed PLA was calculated. 
Once a linear relationship between the degradation rate and temperature was obtained, it was decided to link $t_{0.5 \mathrm{Mw}}$ with the degradation temperature as shown in Figure $14 \mathrm{~b}$. Fitting the $\mathrm{t}_{0.5 \mathrm{Mw}}$ to degradation temperature resulted in a strong linear relationship $\left(R^{2}=0.998\right)$, confirming once again the applicability of accelerated tests to predict the long-term properties of 3Dprinted polymers.
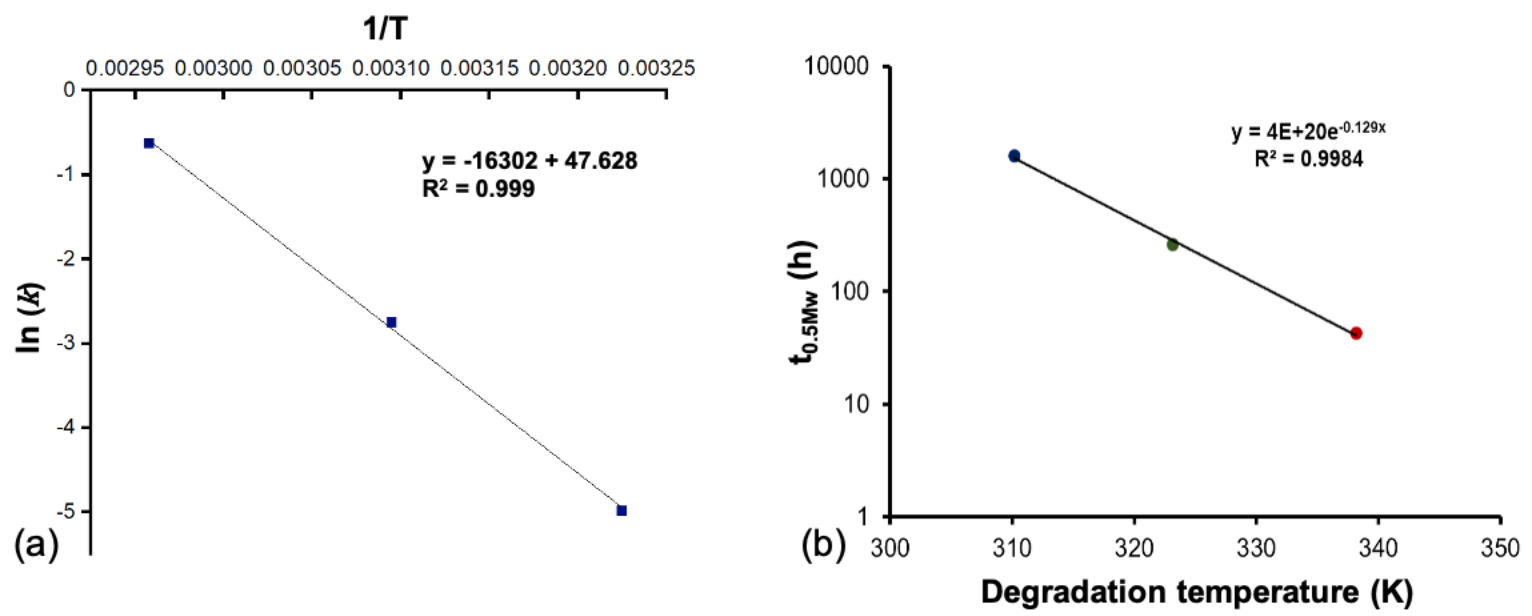

Figure 14 (a) Arrhenius relation for In k against 1/T. (b) Effect of degradation temperature on molecular weight half-life.

For biomedical applications, it is important to choose the initial $M_{w}$ of PLA to achieve the required resorption time; so, the effect of different properties on $M_{n}$ for $F$ and $Z$ specimens were studied at all three temperatures (Figure 15). For all properties except elastic modulus, similar exponential curves can be identified, although at different magnitudes. All mechanical properties showed a considerable change in the slope once the $M_{n}$ value was below $40 \mathrm{kDa}$; meanwhile, for $T_{g}$ this value was around $30 \mathrm{kDa}$. This study developed a rigorous understanding about the effect of molecular weight on mechanical properties, since almost all data points overlapped to a considerable degree even for specimens tested in different directions as well as different temperatures and degradation rates. In addition, these plots can be used as design maps for a range of mechanical-property requirements if the initial polymer molecular weight is known along with its degradation rate. 

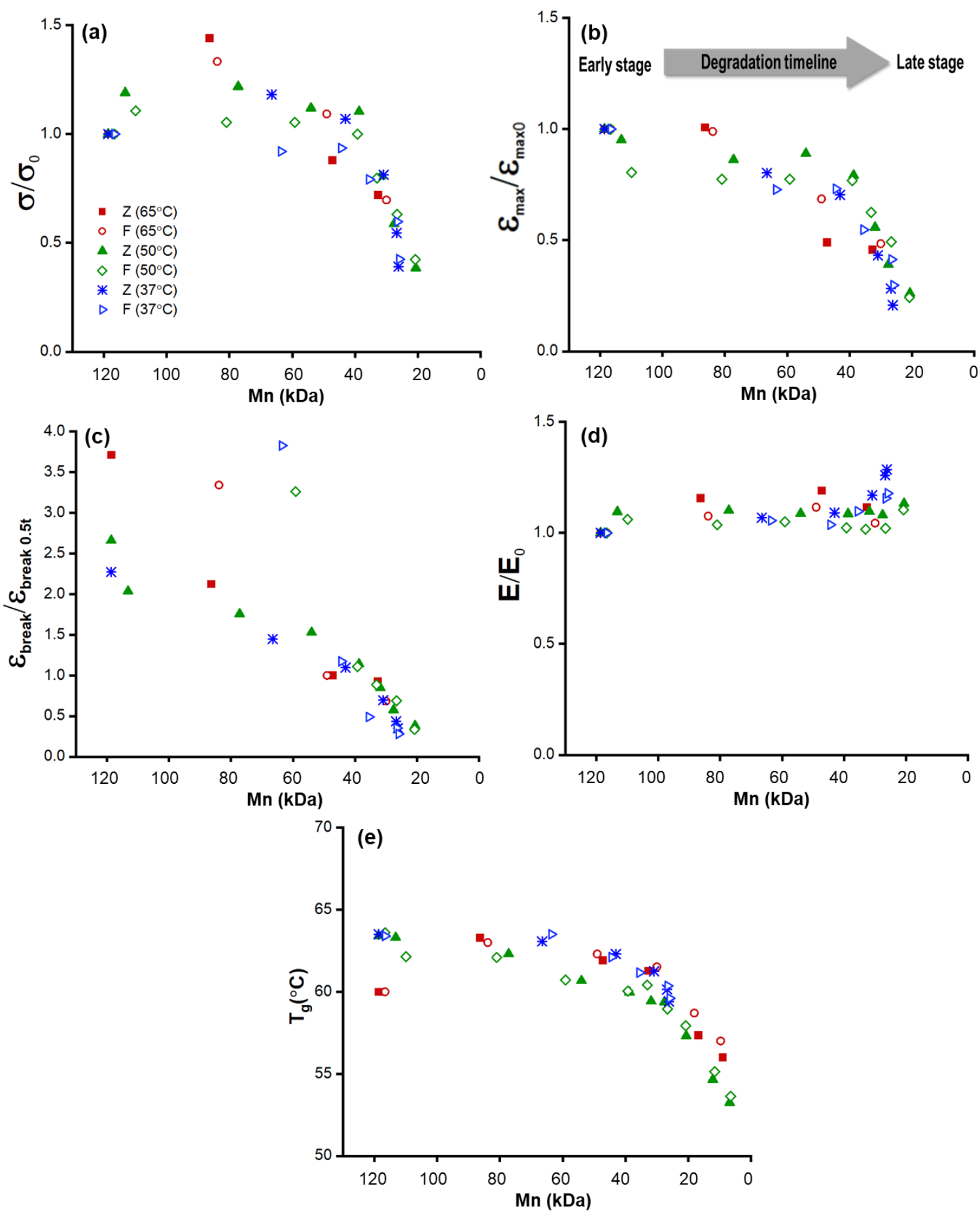

Figure 15 Combined data for normalised strength (a), strain at maximum force (b), strain at break (c), modulus (d) and $T_{g}(e)$ against $M_{n}$ indicating the overlapping of data for degradation temperatures and testing directions. For all properties (except the modulus), an initial plateau period was followed by a sudden decrease, suggesting the existence of a critical $M_{n}$.

\subsection{Fractography analysis}

Fracture analysis is a useful tool for more insight about the effect of degradation on the mechanical performance of the material. This study is the first to link the degradation 
mechanism to the fracture surface of 3D-printed parts. Fractography of undegraded $Z$ specimens (Figure 16a) showed a series of radial striations indicating ductile fracture as explained in [33]. There is no respective image for undegraded $F$ specimens since they did not fail at $40 \%$ strain. After 1 day of degradation at $65^{\circ} \mathrm{C}$, the fracture surface of $Z$ specimen (Figure 16c) demonstrated a flat and smooth surface confirming the transition from ductile to brittle fracture due to the six-fold increase in crystallinity of polymer (Figure 10d). Likewise, F specimens became more brittle after 1 day of degradation and fractured, although some degree of plasticity still happened as indicated by the extensive necking (Figure 16b).

After 3 days of degradation, $F$ specimens (Figure 16d) exhibited more brittle fracture, without necking features, and behaved similarly to $Z$ specimens (Figure 16e) due to a significant increase in crystallinity. The fragments after 5 days (not mechanically tested) were also analysed. Pockets were visible on the surface (as shown by the arrows in Figure $16 \mathrm{f}$ and $\mathrm{g}$ ). These may indicate regions of localised accelerated degradation due to the entrapment of acidic oligomers (Figure $16 \mathrm{f}$ and $\mathrm{g}$ ). This could also explain the slight shoulder observed in the GPC curve for $Z$ specimens after 7 days (Figure 13c) due to faster degradation rate in these localised regions, affecting two degradation conditions. The acidic environments created during degradation could result in release of degradation by-products into the surrounding medium and lowered the $\mathrm{pH}$ from 7.4 to 6.1 , which was noted after $6^{\text {th }}$ day of degradation at $65^{\circ} \mathrm{C}$. The fracture surfaces for the specimens degraded at physiological temperature (Figure 17) showed similar features to $65^{\circ} \mathrm{C}$ i.e. diminished the striations and necking as degradation continued. More detailed fractographic analysis will be considered in a dedicated upcoming study. 


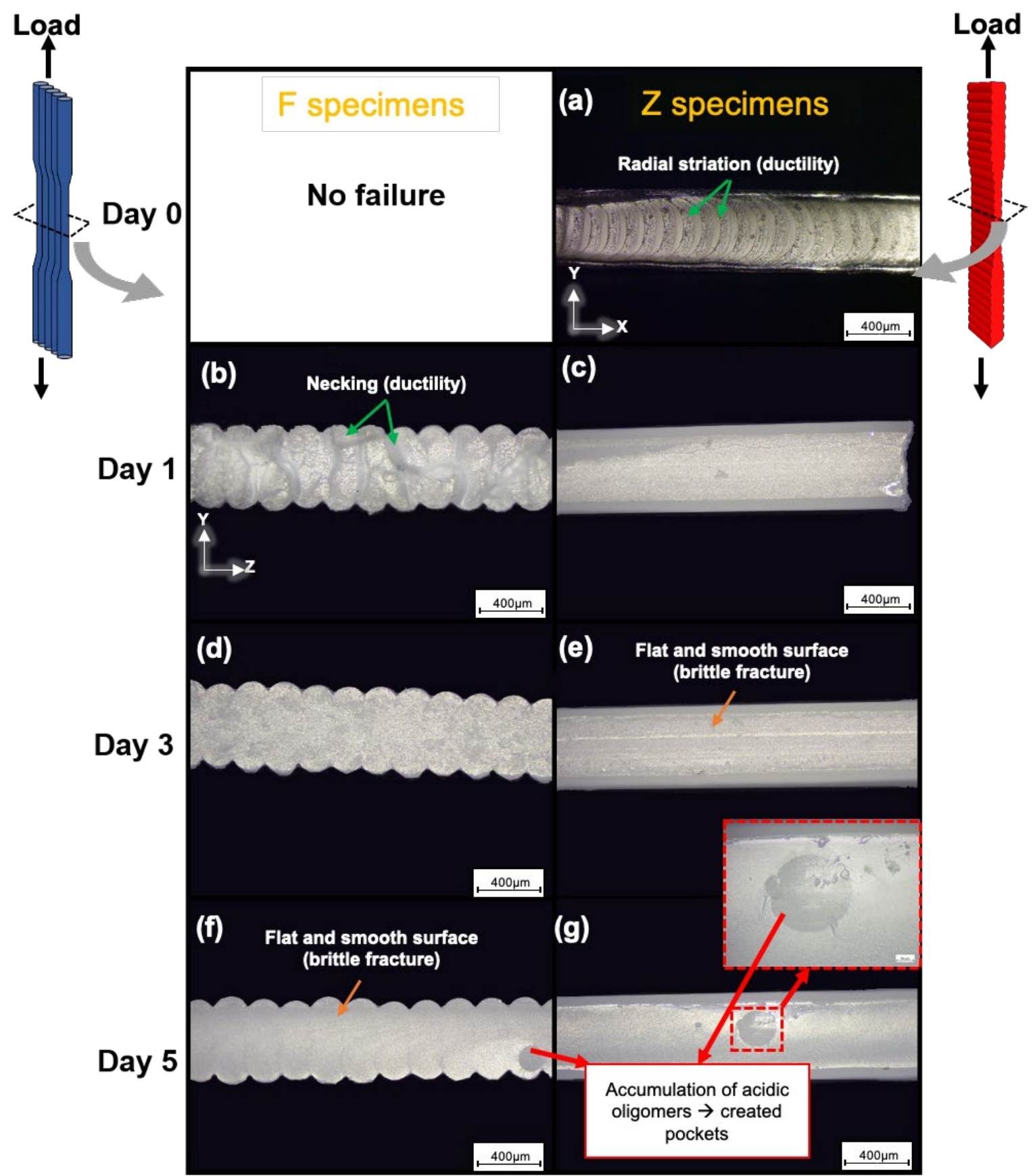

Figure 16 Optical images of fracture surfaces for $F$ (left-hand columns) and Z (right-hand columns) specimens taken at different times when degraded at $65^{\circ} \mathrm{C}$. $F$ specimens at day 0 did not failed up to $40 \%$ strain so no image of fracture surface could be taken. A transition from ductile to brittle fracture by disappearing the necking and striation was observed as degradation continued. Due to autocatalytic degradation and accumulation of acidic oligomers inside polymer, pockets were formed throughout the structure for both $Z$ and $F$ specimens as shown by arrows and inset for the image $g$. 


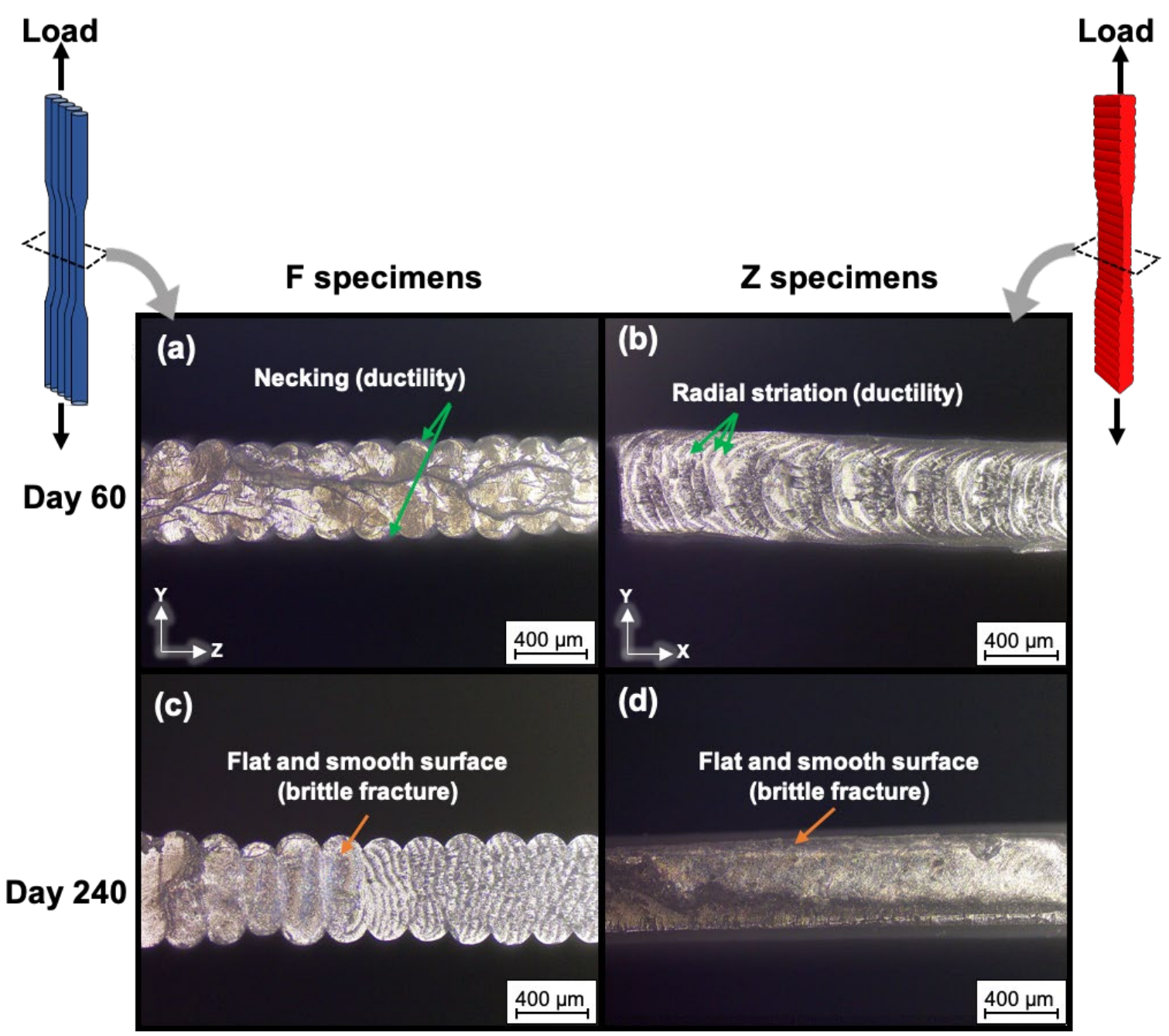

Figure 17 Optical images of fracture surfaces for $F$ (left-hand column) and Z (right-hand column) specimens showing that degradation at $37^{\circ} \mathrm{C}$ changed the mechanical behaviour of polymer by transition from ductile fracture (highlighted by apparent necking and striations) to brittle fracture similar to Figure 16.

\subsection{Advantages, limitations and applicability of findings}

This section discusses the implications and limitations of the current study compared to the literature [26,31]. PLA is widely used for various biomedical applications including fixation plates and stents. Although clinical studies for 3D-printed PLA demonstrated some satisfying early-stage results, it is still necessary to have an understanding of its long-term degradation behaviour and related evolution of mechanical properties, since there is evidence of late-stage complications due to scaffold fracture or discontinuity [62]. Additionally, widespread caution exists with regards to poor bonding between 3D-printed layers. To address and quantify the necessity for this caution, the current study aimed to determine lower and upper bounds of properties by manufacturing the best possible ( $F$ specimens - for bulk properties) and worst ( $Z$ specimens - for interfacial bond properties) orientations. This research demonstrated for the first time the possibility to measure the actual contact area for analysis of properties during 
degradation by employing an appropriate testing design (i.e. single-filament specimens) as opposed to the ASTM standard geometry with non-standardised complex print paths. Based on the obtained results (Section 3.1-4), the interfacial bond degraded in a similar manner to that of bulk material, suggesting that the bond was stable and equivalent to the latter. Rather than poor bonding (as considered in many works e.g. $[26,31,63]$ ), the presence of extrudedfilament-scale geometries was responsible for anisotropic properties, as identified in our previous study [19], and should be the focus of research efforts to reduce anisotropy. Furthermore, the results of this study can be useful for future studies to assess mechanical degradation of biodegradable 3D-printed PLA since, for the first time, mechanical performance under the most medically-relevant conditions (i.e. submerged at $37^{\circ} \mathrm{C}$ ) was characterised.

Although this study focused on mechanical properties of single-filament-wide structures, the results highlight important opportunities for future investigations. Preliminary results of our ongoing research (to be published separately) for more complex print paths indicate that the findings of this research are applicable for a wide range of printing parameters and print paths. Whilst inter-layer bonding is widely considered as the most critical aspect (see e.g. $[63,64]$ ), it would also be interesting to study intra-layer bonding between extruded filaments within a single layer. However, this aspect is not as critical as Z-direction properties since the print path (perimeters and infill pattern) can be designed to orient extruded filaments in the direction of maximum stress, which is not feasible in the $Z$ direction for layer-by-layer manufacturing. Furthermore, in this study, the focus was to precisely characterise the most critical (weakest) aspect of interfacial bond properties: hence, the tensile test was selected as the most appropriate testing mode. Nevertheless, other mechanical testing methods including flexural, compression, shear, cyclic or impact could provide further understanding about a wider range of material behaviours during degradation for specific applications.

Mechanical characterisation is critical for designing new medical implants, but it may also be of value to characterise a range of other factors. Although not in scope of this study (aimed at investigating anisotropic mechanical properties), degradation-induced changes in surface texture are interesting from a biological point of view. The specimens here showed no mesoscale evolution of surface structure or geometry, but future studies could also consider nano- and/or micro-scale surface features. Additionally, PLA in our research underwent bulk degradation (no surface erosion), but co-polymerisation with other polymers or composite materials, or a change in degradation mechanism (e.g. enzymatic degradation), could promote surface erosion. Such a change in degradation kinetics could potentially result in variation of surface texture and geometry over time, consequently affecting the physical and biological properties with respect to wettability and cell-adhesion. 


\section{Conclusions}

This study compared the degradation of the interface bond between filaments ( $Z$ specimen) and bulk polymer (F specimens) for PLA specimens produced by material extrusion additive manufacturing. The sensitivity of 3D-printed PLA to physical ageing at room temperature showed that there was no deterioration of mechanical and thermal properties after 8 months. Hydrolytic degradation experiments demonstrated that the interface between 3D-printed layers degraded in a similar manner to the bulk material. Certain properties such as water absorption, crystallinity and $\mathrm{M}_{\mathrm{w}}$ were sensitive to the degradation temperature increasing from $37^{\circ} \mathrm{C}$ to $65^{\circ} \mathrm{C}$. Mechanical properties, tested under physiological conditions (submerged at $37^{\circ} \mathrm{C}$ ), showed that $Z$ specimens behaved similarly to $F$ specimens at all temperatures, after normalising the degradation time based on molecular weight degradation. This was supported by a detailed analysis of microstructural changes including chemical, thermal and structural properties as well as fractography. Changes in crystallinity of the polymer was shown to greatly influence mechanical properties during the early stage of degradation, while, at the later stage, the properties were affected mainly by $M_{w}$ reduction. The rate of change in $M_{w}$ against degradation temperature obeyed the Arrhenius equation with the calculated activation energy of $135.6 \mathrm{~kJ} \mathrm{~mol}^{-1}$. Comparing properties against $\mathrm{M}_{\mathrm{n}}$ allowed a threshold value of $40 \mathrm{kDa}$ to be identified, below which mechanical properties deteriorated. The findings of this study improve the confidence in using additive manufacturing for biomedical applications since the parts were tested under conditions close to in vivo and showed for the first time that the unavoidable interface between 3D-printed layers did not affect the long-term performance. These findings were only achievable by utilising a specially designed micro-tensile specimen.

\section{Acknowledgements}

This research did not receive any specific grant from funding agencies in the public, commercial, or not-for-profit sectors.

\section{Appendix A. Supplementary data}

PHR values for $Z$ and $F$ specimens for band $920 \mathrm{~cm}^{-1}$ which corresponded to crystallisation dynamics showed an increasing trend with degradation times for both $50^{\circ} \mathrm{C}$ (Figure S1a) and $65^{\circ} \mathrm{C}$ (Figure S1b). 


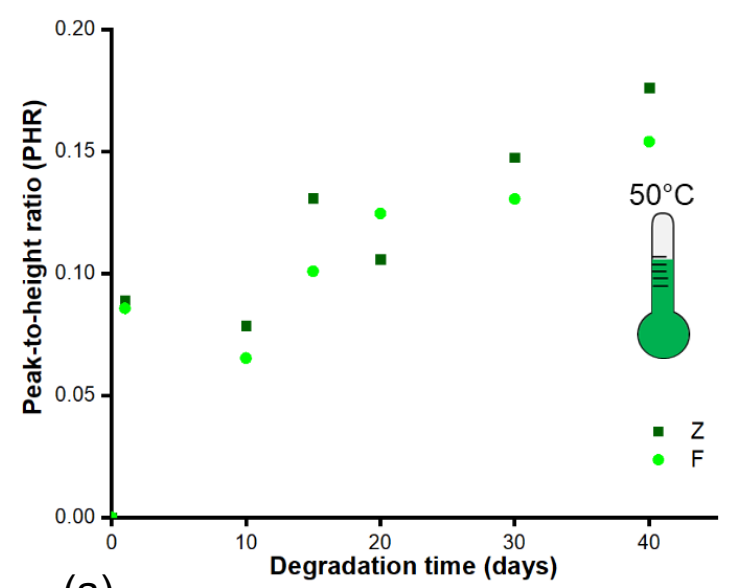

(a)

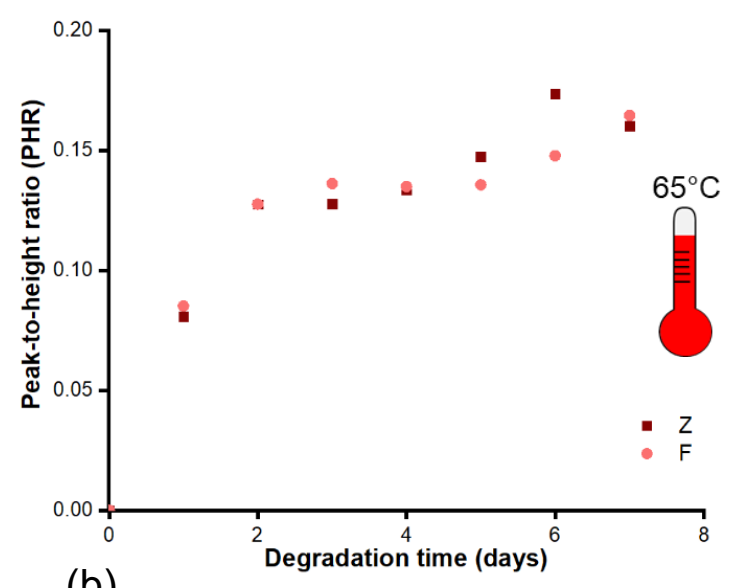

(b)

Figure S1: Evolution of PHR values for band $920 \mathrm{~cm}^{-1}$ for both $Z$ and $F$ degraded at: (a) $50^{\circ} \mathrm{C}$ and (b) $65^{\circ} \mathrm{C}$. No significant differences were found between testing directions.

\section{References}

[1] L.S. Nair, C.T. Laurencin, Biodegradable polymers as biomaterials, Prog. Polym. Sci. 32 (2007) 762-798. https://doi.org/10.1016/j.progpolymsci.2007.05.017.

[2] D. Da Silva, M. Kaduri, M. Poley, O. Adir, N. Krinsky, J. Shainsky-Roitman, A. Schroeder, Biocompatibility, biodegradation and excretion of polylactic acid (PLA) in medical implants and theranostic systems, Chem. Eng. J. 340 (2018) 9-14.

[3] S. Farah, D.G. Anderson, R. Langer, Physical and mechanical properties of PLA, and their functions in widespread applications - A comprehensive review, Adv. Drug Deliv. Rev. 107 (2016) 367-392.

[4] M.A. Elsawy, K.H. Kim, J.W. Park, A. Deep, Hydrolytic degradation of polylactic acid (PLA) and its composites, Renew. Sustain. Energy Rev. 79 (2017) 1346-1352.

[5] L. Safai, J.S. Cuellar, G. Smit, A.A. Zadpoor, A review of the fatigue behavior of 3D printed polymers, Addit. Manuf. 28 (2019) 87-97. https://doi.org/10.1016/j.addma.2019.03.023.

[6] H. Xu, X. Yang, L. Xie, M. Hakkarainen, Conformational footprint in hydrolysisinduced nanofibrillation and crystallization of poly(lactic acid), Biomacromolecules. 17 (2016) 985-995. https://doi.org/10.1021/acs.biomac.5b01636.

[7] A. Gleadall, D. Visscher, J. Yang, D. Thomas, J. Segal, Review of additive manufactured tissue engineering scaffolds: relationship between geometry and performance, Burn. Trauma. 6 (2018) 1-16. https://doi.org/10.1186/s41038-018-0121- 
4.

[8] C. Culmone, G. Smit, P. Breedveld, Additive manufacturing of medical instruments: A state-of-the-art review, Addit. Manuf. 27 (2019) 461-473.

https://doi.org/10.1016/j.addma.2019.03.015.

[9] H. Tsuji, In vitro hydrolysis of blends from enantiomeric poly(lactide)s. Part 4:

wellhomo-crystallized blend and nonblended films, Biomaterials. 24 (2003) 537-547. https://doi.org/https://doi.org/10.1016/S0142-9612(02)00365-4.

[10] H. Tsuji, A. Mizuno, Y. Ikada, Properties and morphology of poly(L-lactide). III. Effects of initial crystallinity on long-term in vitro hydrolysis of high molecular weight poly(Llactide) film in phosphate-buffered solution, J. Appl. Polym. Sci. 77 (2000) 1452-1464. https://doi.org/10.1002/1097-4628(20000815)77:7<1452::AID-APP7>3.0.CO;2-S.

[11] S.K. Saha, H. Tsuji, Effects of rapid crystallization on hydrolytic degradation and mechanical properties of poly(l-lactide-co- $\varepsilon$-caprolactone), React. Funct. Polym. 66 (2006) 1362-1372. https://doi.org/10.1016/j.reactfunctpolym.2006.03.020.

[12] N. Weir, F. Buchanan, J.F. Orr, G.R. Dickson, Degradation of poly-L-lactide. Part 1: in vitro and in vivo physiological temperature degradation, Proc. Inst. Mech. Eng. Part $\mathrm{H}$ J. Eng. Med. 218 (2004) 307-319.

[13] M. Domingos, F. Chiellini, S. Cometa, E. de Giglio, E. Grillo-Fernandes, P. Bartolo, E. Chiellini, Evaluation of in vitro degradation of PCL scaffolds fabricated via BioExtrusion - Part 2: Influence of pore size and geometry, Virtual Phys. Prototyp. 6 (2011) 157-165. https://doi.org/10.1080/17452759.2011.605839.

[14] R.J. Zaldivar, T.D. Mclouth, G.L. Ferrelli, D.N. Patel, A.R. Hopkins, D. Witkin, Effect of initial filament moisture content on the microstructure and mechanical performance of ULTEM ® 9085 3D printed parts, Addit. Manuf. 24 (2018) 457-466. https://doi.org/10.1016/j.addma.2018.10.022.

[15] H. Tsuji, In vitro hydrolysis of blends from enantiomeric poly(lactide)s. Part 1: Wellstereo-complexed blend and non-blended films, Polymer (Guildf). 41 (2000) 36213630. https://doi.org/https://doi.org/10.1016/S0032-3861(99)00545-5.

[16] H. Tsuji, Y. Ikada, Properties and morphology of poly(L-lactide) 4. Effects of structural parameters on long-term hydrolysis of poly(L-lactide) in phosphate-buffered solution, Polym. Degrad. Stab. 67 (2000) 179-189. https://doi.org/10.1016/S01413910(99)00111-1. 
[17] S.C. Ligon, R. Liska, J. Stampfl, M. Gurr, R. Mülhaupt, Polymers for 3D printing and customized additive manufacturing, Chem. Rev. 117 (2017) 10212-10290. https://doi.org/10.1021/acs.chemrev.7b00074.

[18] A. Gleadall, W. Poon, J. Allum, A. Ekinci, X. Han, V. V. Silberschmidt, Interfacial fracture of 3D-printed bioresorbable polymers, Procedia Struct. Integr. 13 (2018) 625630. https://doi.org/https://doi.org/10.1016/j.prostr.2018.12.103.

[19] J. Allum, A. Moetazedian, A. Gleadall, V. V. Silberschmidt, Interlayer bonding has bulk-material strength in extrusion additive manufacturing: New understanding of anisotropy, Addit. Manuf. 34 (2020) 101297. https://doi.org/10.1016/j.addma.2020.101297.

[20] T.J. Coogan, D.O. Kazmer, Bond and part strength in fused deposition modeling, Rapid Prototyp. J. 23 (2017) 414-422. https://doi.org/10.1108/RPJ-03-2016-0050.

[21] M. Spoerk, J. Gonzalez-Gutierrez, J. Sapkota, S. Schuschnigg, C. Holzer, Effect of the printing bed temperature on the adhesion of parts produced by fused filament fabrication, Plast. Rubber Compos. 47 (2018) 17-24. https://doi.org/10.1080/14658011.2017.1399531.

[22] N. Aliheidari, J. Christ, R. Tripuraneni, S. Nadimpalli, A. Ameli, Interlayer adhesion and fracture resistance of polymers printed through melt extrusion additive manufacturing process, Mater. Des. 156 (2018) 351-361. https://doi.org/10.1016/j.matdes.2018.07.001.

[23] C. Bellehumeur, L. Li, Modeling of bond formation between polymer filaments in the fused deposition modeling process, J. Manuf. Process. 6 (2004) 170-178. https://doi.org/10.1016/S1526-6125(04)70071-7.

[24] A. Pan, Z. Huang, R. Guo, J. Liu, Effect of FDM process on adhesive strength of polylactic acid(PLA) filament, Key Eng. Mater. 667 (2015) 181-186. https://doi.org/10.4028/www.scientific.net/KEM.667.181.

[25] M. Spoerk, F. Arbeiter, H. Cajner, J. Sapkota, C. Holzer, Parametric optimization of intra- and inter-layer strengths in parts produced by extrusion-based additive manufacturing of poly(lactic acid), J. Appl. Polym. Sci. 134 (2017) 1-15. https://doi.org/10.1002/app.45401.

[26] J. Gonzalez Ausejo, J. Rydz, M. Musioł, W. Sikorska, H. Janeczek, M. Sobota, J. Włodarczyk, U. Szeluga, A. Hercog, M. Kowalczuk, Three-dimensional printing of PLA and PLA/PHA dumbbell-shaped specimens of crisscross and transverse patterns as 
promising materials in emerging application areas: Prediction study, Polym. Degrad. Stab. 156 (2018) 100-110. https://doi.org/10.1016/j.polymdegradstab.2018.08.008.

[27] C. Casavola, A. Cazzato, V. Moramarco, G. Pappalettera, Residual stress measurement in Fused Deposition Modelling parts, Polym. Test. 58 (2017) 249-255. https://doi.org/10.1016/j.polymertesting.2017.01.003.

[28] M. Barbeck, T. Serra, P. Booms, S. Stojanovic, S. Najman, E. Engel, R. Sader, C.J. Kirkpatrick, M. Navarro, S. Ghanaati, Analysis of the in vitro degradation and the in vivo tissue response to bi-layered 3D-printed scaffolds combining PLA and biphasic PLA/bioglass components - Guidance of the inflammatory response as basis for osteochondral regeneration, Bioact. Mater. 2 (2017) 208-223.

https://doi.org/10.1016/j.bioactmat.2017.06.001.

[29] A. Gregor, E. Filová, M. Novák, J. Kronek, H. Chlup, M. Buzgo, V. Blahnová, V. Lukášová, M. Bartoš, A. Nečas, J. Hošek, Designing of PLA scaffolds for bone tissue replacement fabricated by ordinary commercial 3D printer, J. Biol. Eng. 11 (2017) 121. https://doi.org/10.1186/s13036-017-0074-3.

[30] F. Alam, K.M. Varadarajan, S. Kumar, 3D printed polylactic acid nanocomposite scaffolds for tissue engineering applications, Polym. Test. 81 (2020) 106203. https://doi.org/10.1016/j.polymertesting.2019.106203.

[31] J. Rydz, J. Włodarczyk, J.G. Ausejo, M. Musioł, W. Sikorska, M. Sobota, A. Hercog, K. Duale, H. Janeczek, Three-dimensional printed PLA and PLA/PHA dumbbellshaped specimens: material defects and their impact on degradation behavior, Materials (Basel). 13 (2020) 2005. https://doi.org/10.3390/ma13082005.

[32] ASTM D1708-18, Standard Test Method for Tensile Properties of Plastics By Use of Microtensile, 2002.

[33] A. Moetazedian, A. Gleadall, X. Han, V.V. Silberschmidt, Effect of environment on mechanical properties of 3D printed polylactide for biomedical applications, J. Mech. Behav. Biomed. Mater. 102 (2020) 103510. https://doi.org/https://doi.org/10.1016/j.jmbbm.2019.103510.

[34] A. Moetazedian, A.S. Budisuharto, V. V. Silberschmidt, A. Gleadall, CONVEX (CONtinuously Varied EXtrusion): a new scale of design for additive manufacturing, Addit. Manuf. (2020) 101576. https://doi.org/10.1016/j.addma.2020.101576.

[35] P. Müller, B. Imre, J. Bere, J. Móczó, B. Pukánszky, Physical ageing and molecular mobility in PLA blends and composites, J. Therm. Anal. Calorim. 122 (2015) 1423- 
1433. https://doi.org/10.1007/s10973-015-4831-6.

[36] R. Acioli-Moura, X.S. Sun, Thermal degradation and physical aging of poly(lactic acid) and its blends with starch, Polym. Eng. Sci. 48 (2008) 829-836.

https://doi.org/10.1002/pen.

[37] R. Kotsilkova, P. Angelova, T. Batakliev, V. Angelov, R. Di Maio, C. Silvestre, Study on aging and recover of poly (Lactic) acid composite films with graphene and carbon nanotubes produced by solution blending and extrusion, Coatings. 9 (2019) 1-14. https://doi.org/10.3390/coatings9060355.

[38] J. Allum, A. Gleadall, V. V. Silberschmidt, Fracture of 3D-printed polymers: Crucial role of filament-scale geometric features, Eng. Fract. Mech. 224 (2020) 106818. https://doi.org/10.1016/j.engfracmech.2019.106818.

[39] ISO, Implant for surgery-Homopolymers, copolymers and blends on poly(lactide)- In vitro degradation testing, 2017.

[40] B. Tymrak, M. Kreiger, L. Pearce, P. Khalili, X. LIU, Z. ZHAO, B. Blinzler, Fully biodegradable composites: thermal, flammability, moisture absorption and mechanical properties of natural fibre-reinforced composites with nano-hydroxyapatite, Materials (Basel). 12 (2019) 1145. https://doi.org/10.3390/ma12071145.

[41] ASTM D570-98, Standard Test Method for Water Absorption of Plastics, 2010. https://doi.org/10.1520/D0570-98R10E01.2.

[42] O. Vyavahare, D. Ng, S.L. Hsu, Analysis of structural rearrangements of poly(lactic acid) in the presence of water, J. Phys. Chem. B. 118 (2014) 4185-4193. https://doi.org/10.1021/jp500219j.

[43] R. Naseem, L. Zhao, V. Silberschmidt, Y. Liu, O. Scaife, H. Willcock, S. Eswaran, S. Hossainy, Mechanical and chemical characterisation of bioresorbable polymeric stent over two-year in vitro degradation, J. Biomater. Appl. 34 (2019) 61-73. https://doi.org/10.1177/0885328219839591.

[44] R.M. Felfel, K.M.Z. Hossain, A.J. Parsons, C.D. Rudd, I. Ahmed, Accelerated in vitro degradation properties of polylactic acid/phosphate glass fibre composites, J. Mater. Sci. 50 (2015) 3942-3955. https://doi.org/10.1007/s10853-015-8946-8.

[45] N.A. Weir, F.J. Buchanan, J.F. Orr, D.F. Farrar, G.R. Dickson, Degradation of poly-Llactide. Part 2: Increased temperature accelerated degradation, Proc. Inst. Mech. Eng. Part H J. Eng. Med. 218 (2004) 321-330. 
https://doi.org/10.1243/0954411041932809.

[46] D. Wang, P.M. Fredericks, A. Haddad, D.J.T. Hill, F. Rasoul, A.K. Whittaker, Hydrolytic degradation of POSS-PEG-lactide hybrid hydrogels, Polym. Degrad. Stab. 96 (2011) 123-130. https://doi.org/10.1016/j.polymdegradstab.2010.10.005.

[47] M. Oliveira, E. Santos, A. Araújo, G.J.M. Fechine, A. V. Machado, G. Botelho, The role of shear and stabilizer on PLA degradation, Polym. Test. 51 (2016) 109-116. https://doi.org/10.1016/j.polymertesting.2016.03.005.

[48] P. Pan, B. Zhu, Y. Inoue, Enthalpy relaxation and embrittlement of poly(L-lactide) during physical aging, Macromolecules. 40 (2007) 9664-9671.

https://doi.org/10.1021/ma071777c.

[49] Y.P. Koh, S.L. Simon, Enthalpy recovery of polystyrene: Does a long-term aging plateau exist?, Macromolecules. 46 (2013) 5815-5821.

https://doi.org/10.1021/ma4011236.

[50] R.M. Felfel, I. Ahmed, A.J. Parsons, G.S. Walker, C.D. Rudd, In vitro degradation, flexural, compressive and shear properties of fully bioresorbable composite rods, J. Mech. Behav. Biomed. Mater. 4 (2011) 1462-1472. https://doi.org/10.1016/j.jmbbm.2011.05.016.

[51] T. Hayashi, Biodegradable polymers for biomedical uses, Prog. Polym. Sci. 19 (1994) 663-702. https://doi.org/10.1016/0079-6700(94)90030-2.

[52] P. Kakanuru, K. Pochiraju, Moisture Ingress and Degradation of Additively Manufactured PLA, ABS and PLA/SiC Composite Parts, Addit. Manuf. (In press) (2020) 101529. https://doi.org/10.1016/j.addma.2020.101529.

[53] N. Burgos, D. Tolaguera, S. Fiori, A. Jiménez, Synthesis and characterization of lactic acid oligomers: evaluation of performance as poly(lactic acid) plasticizers, J. Polym. Environ. 22 (2014) 227-235. https://doi.org/10.1007/s10924-013-0628-5.

[54] J. Zhang, D.X. Yan, J.Z. Xu, H.D. Huang, J. Lei, Z.M. Li, Highly crystallized poly (lactic acid) under high pressure, AIP Adv. 2 (2012) 042159.

https://doi.org/10.1063/1.4769351.

[55] H. Tsuji, Autocatalytic hydrolysis of amorphous-made polylactides: Effects of L-lactide content, tacticity, and enantiomeric polymer blending, Polymer (Guildf). 43 (2002) 1789-1796. https://doi.org/10.1016/S0032-3861(01)00752-2.

[56] A. Gleadall, J. Pan, M.A. Kruft, M. Kellomäki, Degradation mechanisms of 
bioresorbable polyesters. Part 2. Effects of initial molecular weight and residual monomer, Acta Biomater. 10 (2014) 2233-2240.

https://doi.org/10.1016/j.actbio.2014.01.017.

[57] A. Gleadall, J. Pan, M.A. Kruft, M. Kellomäki, Degradation mechanisms of bioresorbable polyesters. Part 1. Effects of random scission, end scission and autocatalysis, Acta Biomater. 10 (2014) 2223-2232. https://doi.org/10.1016/j.actbio.2013.12.039.

[58] A. Gleadall, J. Pan, H. Atkinson, A simplified theory of crystallisation induced by polymer chain scissions for biodegradable polyesters, Polym. Degrad. Stab. 97 (2012) 1616-1620. https://doi.org/10.1016/j.polymdegradstab.2012.06.023.

[59] C. Agrawal, D. Huang, J. Schmitz, A. KA, Elevated temperature degradation of a 50:50 copolymer of PLA-PGA, Tissue Eng. 3 (1997) 345. https://doi.org/https://doi.org/10.1089/ten.1997.3.345.

[60] W.S. Pietrzak, M. Kumar, B.L. Eppley, The influence of temperature on the degradation rate of LactoSorb copolyme, J. Craniofac. Surg. 14 (2003) 176-183.

[61] R.M. Felfel, L. Poocza, M. Gimeno-Fabra, T. Milde, G. Hildebrand, I. Ahmed, C. Scotchford, V. Sottile, D.M. Grant, K. Liefeith, In vitro degradation and mechanical properties of PLA-PCL copolymer unit cell scaffolds generated by two-photon polymerization, Biomed. Mater. 11 (2016) 15011. https://doi.org/10.1088/1748$6041 / 11 / 1 / 015011$.

[62] A. Patel, T. Nazif, G. Stone, Z. Ali, Intraluminal bioresorbable vascular scaffold dismantling with aneurysm formation leading to very late thrombosis, Catheter. Cardiovasc. Interv. 89 (2017) 876-879. https://doi.org/https://doi.org/10.1002/ccd.26913.

[63] J.M. Chacón, M.A. Caminero, E. García-Plaza, P.J. Núñez, Additive manufacturing of PLA structures using fused deposition modelling: Effect of process parameters on mechanical properties and their optimal selection, Mater. Des. 124 (2017) 143-157.

[64] X. Gao, S. Qi, X. Kuang, Y. Su, J. Li, D. Wang, Fused filament fabrication of polymer materials: A review of interlayer bond, Addit. Manuf. (2020) 101658. https://doi.org/10.1016/j.addma.2020.101658. 